\title{
Earthquake Resistance of Adobe Reinforced by Low Cost Traditional Materials
}

\author{
Mohammad Shariful IsLam* \\ Kazuyoshi IwaShitA** \\ *Department of Civil Engineering, Bangladesh University of Engineering and Technology \\ **Professor, Department of Civil and Environmental Engineering, Saitama University
}

(Received December 25 . 2008 accepted July 8 . 2010)

\begin{abstract}
Adobe houses are expected to continue providing the housing needs of rural poor people because of their energy efficiency, comfort, and cost effectiveness. Unfortunately traditional adobe constructions are very poor against earthquakes and cause significant loss of life and property. Seismic deficiencies of such structures are mainly due to brittleness and low strength of the blocks; low strength as well as poor bonding of mortar; and lack of structural integrity. Considering affordability, availability, environmental friendliness and easy construction, the current study adopts natural fibers (straw, hemp and jute) and cementing materials (cement and gypsum) as reinforcing materials to improve the strength and ductility of adobe material. Straw improves the ductility of adobe block at the cost of compressive strength. Jute is the most effective among the selected fibers to improve both the ductility and toughness of adobe block. Gypsum improves the strength of adobe block but not the ductility. Similarly, cement is effective for improving the mortar strength only. On the contrary, jute is effective for improving the mortar strength as well as coherence between block and mortar. Higher flexibility, tensile strength and friction of jute might be the reason for its best performance.
\end{abstract}

Keyword: adobe, ductility, low cost, toughness, and natural fiber

\section{INTRODUCTION}

Adobe is one of the oldest and most widely used building materials for its manifold advantages such as, low cost, easy availability, easy construction, low energy requirement, and environment friendliness. Moreover, its excellent thermal and acoustic properties make it appropriate for areas with severe weather conditions and a high range of temperature variation. Approximately $30 \%$ of the world's population and $50 \%$ of the population in developing countries still live in earthen dwellings (Houben and Guillaud,
1994). However, traditional adobe construction responds very poorly to earthquakes; suffers serious structural damage or collapse and causes significant loss of life and property. The 2001 Gujarat earthquake in India and the December 26, 2003 Bam earthquake in Iran bear ample testimony to this fact. In spite of this, due to different socio-economic reasons and unavailability of suitable alternatives, these structures are expected to continue to exist for decades to come, especially in developing countries. But unfortunately only a few studies have focused on the development of earthquake resistant reinforcement of such struc- 
tures.

So, why do adobe structures fail? The response of adobe structures in past earthquakes and the causes of their failure are described in many reports (e.g., Boduroglu, 1989; Tomaževič, 1999; Tolles et al., 1996). These reports indicate that the damage to adobe structures is mainly due to tensile failure of the mortar. However, past earthquakes indicate that adobe structures generally fail due to the following reasons:

- Adobe is a brittle material although it may have large compressive strength. Once yielding occurs, cracks develop in the adobe and a complete loss of tensile strength results.

- Unreinforced mortar is extremely weak and the connection between block and mortar is poor. This results in a partial or total disintegration under a few cycles of shaking of a moderate earthquake.

- Heavy mass inducing great inertial force and configuration of the walls derives an unstable structure.

- Lack of structural integrity (i.e., sufficient strong connections between various elements of the structure).

State-of-the-art research studies and field applications indicate that seismic resistance of adobe structures can be improved in two ways: 1) improving the structural integrity using structural reinforcement and (2) improving block and mortar properties (i.e., strength, ductility, toughness as well as bonding between block and mortar).

Efforts have been made by different researchers in the past to improve the seismic resistance of adobe structures using structural reinforcement such as concrete beams, anchored roof beams, horizontal and vertical steel rods, welded wire mesh, steel mesh with cement mortar, tensile steel bars, etc. (Meli et al., 1980; Scawthorn and Becker, 1986; Ottazzi et al., 1988; Bariola and Sozen, 1990; Ginnell et al., 1995; Tolles et al., 2000). Possibilities of using locally available cane and wood beams have also been explored (Arya, 2000). The effectiveness of PP-Band mesh and polymer mesh has been evaluated recently (Paola et al., 2006; Blondet et al., 2006). Among several methods available for the seismic reinforcement of adobe structures, the most common are-horizontal and vertical bamboo/cane reinforcement, timber beam, con- crete beam and wire mesh. The cost of reinforcing an adobe structure of an ideal configuration $(9.0 \mathrm{~m} \times 6.0$ $\mathrm{m} \times 2.9 \mathrm{~m}$ ) using these four methods has been estimated based on the local price (PWD Schedule, 2002) in Bangladesh, which is a developing country. Details of the reinforcements are available in Blondet et al. (2003). The cost of reinforcement varies between 150 580 US \$. Comparison of the costs of such reinforcements using the Gross National Income (GNI) per person of the developing countries (e.g., GNI of Bangladesh is 394 US \$, World Bank Statistics, 2004) indicates that none of these methods would be affordable for low income people. PP-band and polymer meshes are cost effective solutions. But these are not biodegradable; therefore, if disposed of after failure, these meshes may produce natural hazards.

Therefore, the structural reinforcement techniques described above are not feasible methods to apply to adobe structures for developing countries due to their high cost, requirement for skilled design and construction as well as environmental hazard. Hence, finding a feasible and an implementable solution for the earthquake resistant reinforcement of adobe structures for developing countries is a very important issue.

Adobe home-makers have been using natural fibers such as straw and grass traditionally with adobe as reinforcement material for centuries (Hossein-Javaheri, 1972; Hammond, 1973). Straw is an agricultural waste, very cheap, easily available worldwide and environmentally friendly. However, although used for millennia, there are only a few analytic studies on earth/straw mixtures (Vargas et al., 1986; Morris, 1993; Warren, 1999; Islam, 2002; Binici et al., 2005; Islam et al., 2006). These studies mainly focused on strength characteristics, crack control, and moisture resistance of adobe material. However, short discontinuous fibers have the advantage of mixing with the matrix homogeneously. Therefore, fibers might be effective for improving the properties of adobe block and mortar in the following way:

- Fibers might be effective for increasing the tensile strength and elasticity of the material. They will also help to prevent the cracks in adobe block and mortar during drying.

- The sewing action of fibers may provide better co- 
herence between the block and the mortar.

- Fibers in the matrix will provide a means to prevent the crack growth in the shear band when cracks propagate due to the imposed loads. Thus fibers can improve the ductility, toughness, or both, and flexural strength of the block.

- Moreover, the addition of fibers will reduce the density of the material, which will help to reduce the inertia forces.

None of these past investigations described above examined the effectiveness and mechanisms of the addition of straw to adobe material on ductility, toughness and bonding characteristics, which are the key issues to improve their earthquake resistance. However, different kinds of natural fibers are available in different parts of the world. It is worth comparing the effectiveness of the performance of the straw reinforced adobe with that of other natural fibers to select the most suitable fiber type. Natural fibers such as jute and hemp are stronger, more flexible than straw and have high friction to soil particles. They are easy to find, cheap and do not produce any environmental hazard. Huge quantities of jute are available in India and Bangladesh where adobe houses are being used significantly. Hemp is produced in many countries such as China, Hungary, Canada, and the USA.

Cementing materials such as cement, lime and gypsum are also mixed traditionally with adobe to improve strength characteristics. Gypsum stabilized adobe showed better performance in past earthquakes (Brown et al., 1978). Gypsum is being used with adobe in Turkey (Hammond, 1973; Isik et al., 1999). The cost of gypsum depends on the availability. Although gypsum is cheap and easily available in some countries, it might be costly and not available in other countries. However, gypsum is related to cement in terms of its cementing effect. Although cement is expensive, it is readily available worldwide. The effect of gypsum on adobe was investigated recently by Isik et al., 1999; Islam, 2002; and Binici et al., 2005. However, these studies focused mainly on the strength characteristics. Gypsum and cement might be effective in the following way:

- Gypsum expands in volume while drying. Therefore, a judicial blend of gypsum with earth might be effective for preventing the shrinkage cracks in adobe block and mortar during drying.

- Both gypsum and cement might be effective for improving the strength of adobe block and mortar as well as coherence between block and mortar due to their cohesive properties.

None of these past studies stated above clarified the effectiveness of cementing materials on ductility, toughness, and the coherence of block and mortar.

Considering the affordability, availability, environmental friendliness, and ease of construction the current study focuses only on the improvement of adobe block and mortar properties using natural fibers (i.e., straw, hemp and jute) and cementing materials (i.e., gypsum and cement). These materials have been used with adobe traditionally and will be accepted by home-makers if there are benefits.

Adobe home-makers use the locally available soil to make adobe. Therefore, it is necessary to investigate the effect of soil composition on the performance of the proposed reinforcing materials, especially the clay content, which gives the maximum strength to the soil.

There is always a gap between the material properties determined from the laboratory tests and the real material properties for several reasons (e.g., size, shape, making condition). Among these reasons, difference in the size of the specimen and size of the real unit in the structure is the most important.

This study focuses on the improvement of block and mortar properties of adobe structures. Uniaxial compression tests were conducted on block and sandwich specimens (two adobe blocks joined with mortar) to evaluate the effectiveness of the proposed reinforcing materials on adobe block and mortar properties (strength, ductility, toughness and coherence between block and mortar), respectively. Therefore, the test results describe the behavior of block and mortar only. Further tests (cyclic or dynamic) are required to obtain parameters that can be used for the analysis of adobe structures under earthquake excitation. However, better strength and ductility of block and mortar mean that the structure will perform better 
under earthquake loading. The main objectives of this investigation are:

a) To evaluate the effectiveness and mechanism of straw as an earthquake resistant reinforcing material for adobe. To investigate the influence of quantity, size in length and type (crushed or uncrushed) of straw on the seismic behavior of adobe block.

b) To compare the characteristics of straw reinforced adobe with that of jute and hemp reinforced adobe to select the best suitable natural fiber type as the reinforcing material and thus to understand its mechanism. To determine the optimum quantity and length of the most suitable fiber.

c) The effect of soil composition and scale of test specimens on the effectiveness of the proposed reinforcing materials.

d) The effectiveness of cementing materials (gypsum and cement) to improve the earthquake resistance of adobe.

\section{EXPERIMENTAL PROGRAM}

\subsection{Testing and Indices}

\subsubsection{Test Procedure}

Uniaxial compression tests were conducted to evaluate the effectiveness of the proposed fibers and cementing materials on the earthquake resistance of adobe. All tests were conducted by a chain of devices composed of a loading device, a digital acquiring device, and a personal computer. Load values were measured with a load cell of $20 \mathrm{kN}$ capacity. Strain was calculated from the strain rate and time. For each group, at least 3 specimens were tested to check the repeatability of the test results. All tests were conducted in accordance with JIS A 1216 (JGS, 1999). Compressive strength, failure strain, and ultimate failure point were determined from the stress-strain relationships. To compare the effectiveness of the proposed reinforcing materials, ductility and toughness were estimated from the stress-strain relationships.

\subsubsection{Definition of Parameters}

(1) Compressive strength, Failure strain, Ultimate Failure Point

Compressive strength is defined as the peak stress on the stress-strain curve. If there is no peak in the stress-strain curve up to $15 \%$ strain, then stress corresponding to the $15 \%$ strain is taken as the compressive strength. Failure strain is defined as the strain corresponding to the peak stress and $15 \%$ if there is no peak before $15 \%$ strain. Figure 1a shows the compressive strength, failure strain, and ultimate failure point of the stress-strain relationship according to JIS A 1216 (JGS, 1999). As presented in Fig. 1a, the ultimate failure point corresponds to the $2 / 3 \mathrm{q}_{\mathrm{u}}$ (where, $\mathrm{q}_{\mathrm{u}}$ is compressive strength), at $2.0 \%$ from the peak and $15.0 \%$ for Case I, II and III, respectively.

\section{(2) Ductility}

Ductility $(\mu \mathrm{D})$ is defined as the relationship of a total elasto-plastic response deformation related to the deformation in the elastic limit (Krätzig and Meskouris, 1998) as stated in Equation 1. This can only be defined for linear elastic, fully plastic responses. But for real materials, the response graphs become curvilinear and the fixing of the elastic limit involves considerable uncertainty (Fig. 1b). As a result, defining ductility contains many ambiguities. In spite of this, ductility was estimated using Equation 1 to compare the performances of the proposed reinforcing material. Displacement (i.e., strain) corresponding to the $\mathrm{q}_{\mathrm{u}} / 2$ is taken as the elastic limit of displacement. In the case of soils, elastic modulus $\left(\mathrm{E}_{50}\right)$ is determined from the ratio of the $\mathrm{q}_{\mathrm{u}} / 2$ and the strain corresponding to it. Hence, choosing the strain corresponding to the $\mathrm{q}_{\mathrm{u}} / 2$ as elastic limit is reasonable. Displacement (i.e., strain) equal to the ultimate failure point was taken as the ultimate limit of displacement.

$$
\mu_{D}=\frac{u_{u l t}}{u_{e l}}
$$

where, $u_{e l}$ and $u_{u l t}$ are elastic limit and ultimate limits of displacements (i.e., strain), respectively.

Ductility has also been estimated using the energy concept. In this method, elastic energy and plastic energy were calculated from the stress-strain relationship as shown in Fig. 1c. Definition of ductility $\left(\mu_{\mathrm{E}}\right)$ according to this method is presented in Equation 2.

$$
\mu_{E}=\frac{W_{p}}{W_{e}}
$$

where, $W_{e}$ and $W_{p}$ are elastic and plastic energy, respectively. 
(a)

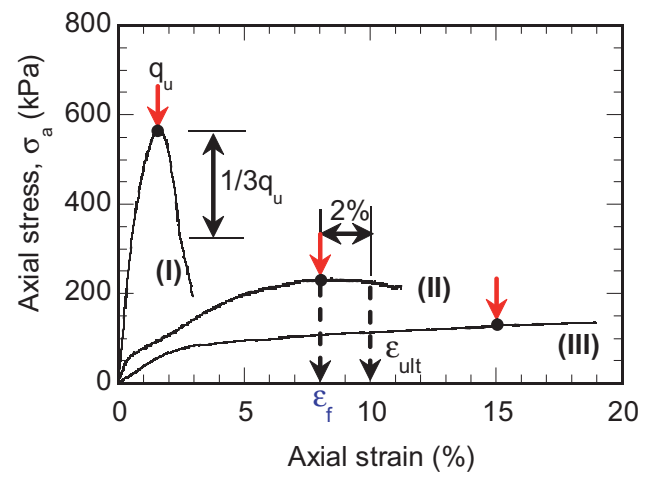

(c)

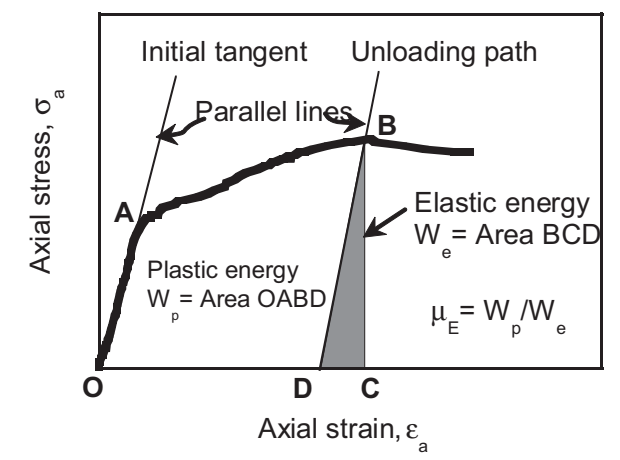

(b)
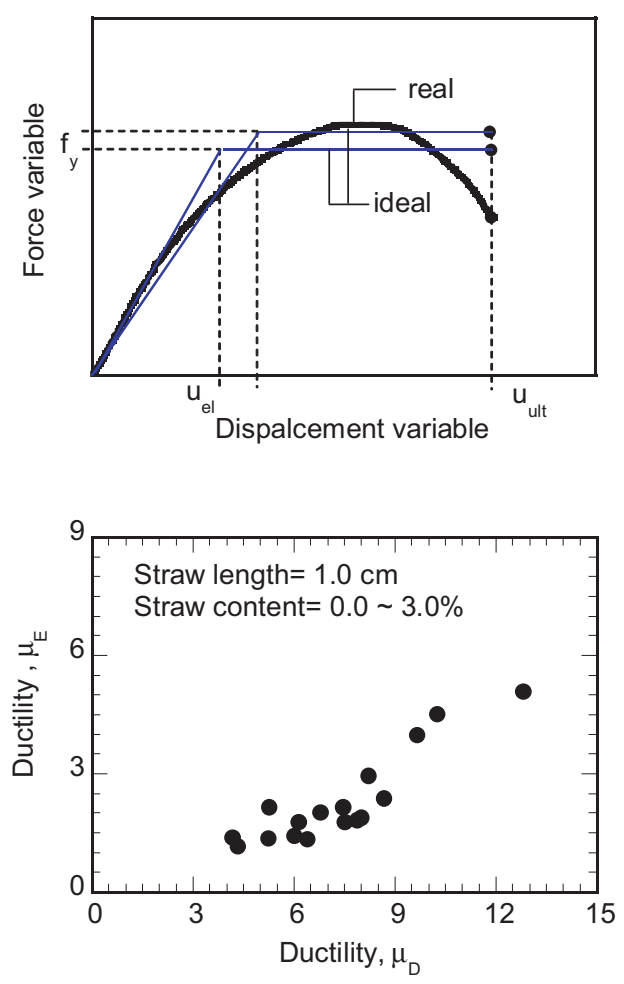

Fig. 1 (a) Definition of compressive strength, failure strain and ultimate failure strain (point marked by arrow $[\downarrow]$ on the stress-strain curve indicates the compressive strength and corresponding strain is failure strain; strain corresponding to the dot $[\bullet]$ on the stress-strain diagram is ultimate failure strain) according to JIS A1216 (JGS, 1999). Definition of: (b) ductility, $\mu_{\mathrm{D}}$; (c) ductility, $\mu_{\mathrm{E}}$ and (d) comparison of $\mu_{\mathrm{D}}$ and $\mu_{\mathrm{E}}$.

Ductility estimated from the displacement (i.e., strain) and energy based on Equations 1 and 2 is denoted as $\mu_{\mathrm{D}}$ and $\mu_{\mathrm{E}}$ hereafter. A comparison of ductility estimated from both equations is presented in Fig. 1d. Both ductilities showed a similar trend. Therefore, ductility estimated from the displacement was only used for the comparison of performances.

\section{(3) Toughness}

Toughness is a measure of the combination of ductility and strength. The ability of a material to absorb energy before fracture is termed as toughness. Toughness is calculated as the area under the stressstrain curve up to the ultimate failure point as shown in Fig. 1a.

\subsection{Materials Used}

\subsubsection{Soils}

Ideally, the soil to make adobe must contain four elements: coarse sand or aggregate, fine sand, silt, and clay. Since this investigation was conducted at Saitama University in Japan, locally available Japa- nese soils were used to make adobe. To determine the general adobe composition, some old adobe collected from Choga Zanbil Temple (which is a world heritage site located in the western part of Iran) was studied. Dry density and water content of the old adobe are in the range of $2.71 \sim 2.76 \mathrm{~g} / \mathrm{cm}^{3}$ and $1.40 \sim 5.10 \%$, respectively. More details about the old adobe are available in Islam (2002). To attain similar grain size distributions of the old adobe, locally available Japanese Acadama clay, Toyoura sand, and Bentonite were mixed with a weight ratio of 2.5:1.0:0.6. This mixture was named the 'soil-sand mixture' (SSM) in the current investigation. To understand the effect of the soil composition on the behaviour of the adobe, specimens were also prepared using Kaolin clay instead of Bentonite clay. Physical properties of the soils used for making adobe are presented in Table 1. Chemical composition of the soils is available in Islam (2002). Grain size distribution of the 'soil-sand mixture' and those of the old adobe are compared in Fig. 2. The grain size distribution of the 'soil-sand mixture' is similar to that of the old adobe specimens. 
Table 1. Physical properties of soils

\begin{tabular}{l|c|c|c|c}
\hline Soil & $\begin{array}{c}\text { Specific } \\
\text { gravity }\end{array}$ & $\begin{array}{c}\text { Liquid limit } \\
(\%)\end{array}$ & $\begin{array}{c}\text { Plastic limit } \\
(\%)\end{array}$ & $\begin{array}{c}\text { Plasticity index } \\
(\%)\end{array}$ \\
\hline Acadama clay & 2.65 & 145.0 & 67.0 & 78.0 \\
Toyoura sand & 2.51 & - & - & - \\
Bentonite & 2.51 & 232.0 & 31.0 & 201.0 \\
Kaolin & 2.65 & 84.5 & 34.5 & 50.0 \\
SSM & 2.62 & 70.0 & 35.0 & 35.0 \\
\hline
\end{tabular}

\section{(3) Hemp}

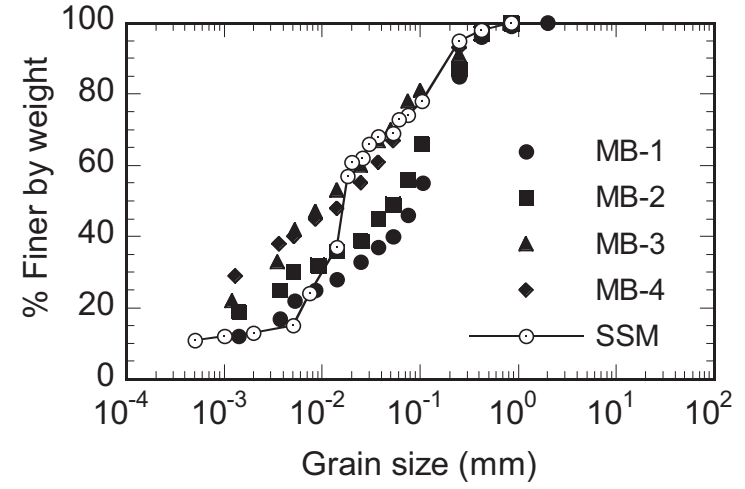

Fig. 2 Grain-size distributions of old adobe collected from Iran (MB) and soil-sand mixture (SSM) used for making adobe.

\subsubsection{Reinforcing materials}

(1) Straw

Straw is an agricultural by-product, the dry stalk of a cereal plant, after the nutrient grain or seed has been removed. Straw makes up about half of the yield of a cereal crop such as barley, oats, rice, rye or wheat. The internal structure of a single straw is tubular, tough, flexible, and has high tensile strength. In this investigation, fully dried rice straw was used after chopping into short pieces as shown in Fig. 3a.

\section{(2) Jute}

Jute fiber is collected from jute stems. Jute fiber is flexible, rough and has high tensile strength. Jute, which is an annual plant produced in tropical countries such as Bangladesh, India, grows about 2 3 $\mathrm{m}$ in 4 months. Since jute is not produced in Japan, commercially available jute was used in this investigation after chopping it into short pieces as shown in Fig. 3 b.
Hemp is also collected from the hemp plant, which is an annual plant. It grows about $3 \sim 4 \mathrm{~m}$ in 110 days and its stem diameter is $2 \sim 3 \mathrm{~cm}$. Hemp originates from central Asia, and is now available worldwide. Its production per unit area is relatively high. In this case, commercially available hemp was also used. Hemp was also used in the form of jute as shown in Fig. $3 b$.

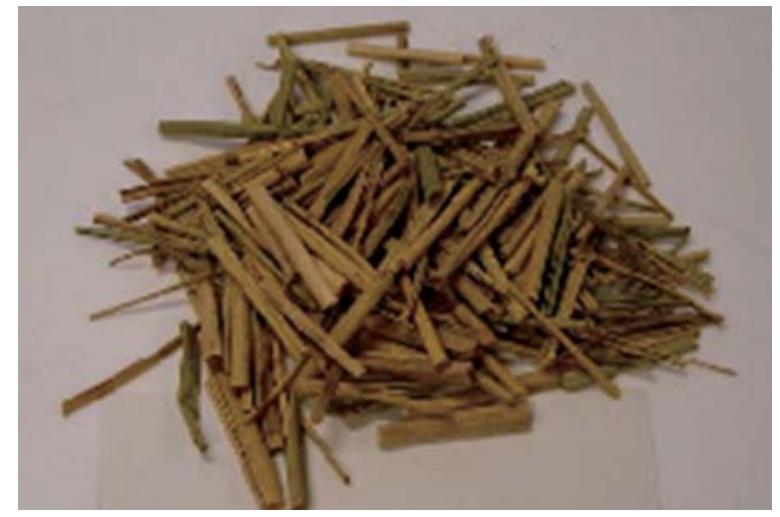

(a)

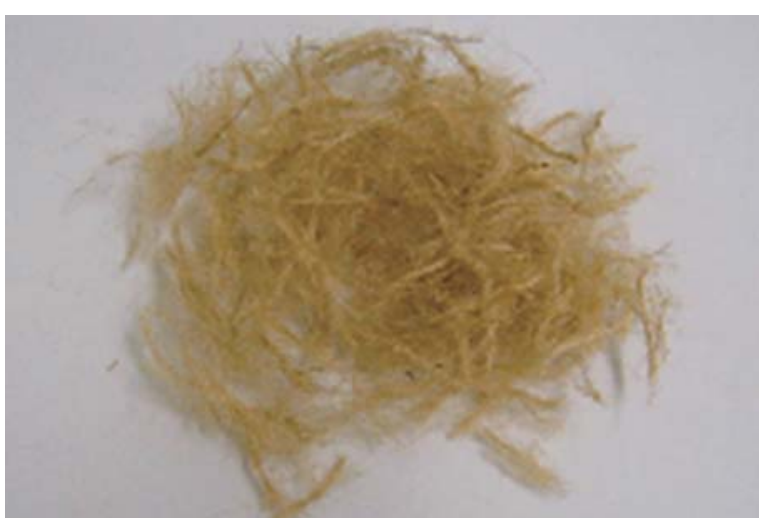

(b)

Fig. 3 Photographs of chopped: (a) straw and (b) jute. 


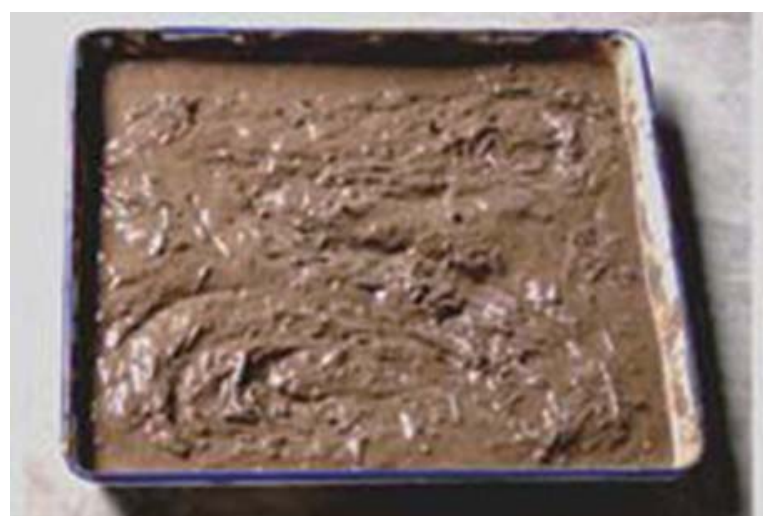

(a)

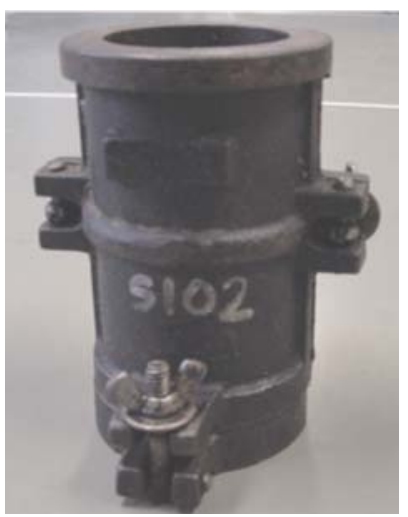

(b)

Fig. 4 Photographs of: (a) soil-sand slurry and (b) steel mould.

\section{(4) Gypsum}

Gypsum is a very soft mineral composed of calcium sulphate dihydrate, with the chemical formula $\mathrm{CaSO}_{4} \cdot 2 \mathrm{H}_{2} \mathrm{O}$. Commercially available gypsum was used in this investigation. The specific gravity of the gypsum used is 2.30 .

\section{(5) Cement}

In the case of cement, ordinary Portland cement was used. The specific gravity of the cement is 3.16.

\subsection{Preparation of Specimens}

Adobe is a sun dried brick. Generally, it takes 2 3 weeks to obtain dried adobe. The water content of dried adobe is about 3.0\%. Cylindrical block and sandwich specimens were prepared to evaluate the effectiveness of the proposed reinforcing materials on block and mortar characteristics.

\subsubsection{Block Specimen}

First of all, Acadama clay was cleaned of unwanted materials, air-dried, and then reduced to powder. After mixing the clay with reinforcing materials and soils in dry conditions, water content equaling 1.5 times the liquid limit (LL) of the 'soil-sand mixture' was added. Then it was mixed vigorously by hand to make the mixture homogeneous. The slurry (Fig. 4a) was kept for 1 day for the complete dispersion of the clay particles. On the following day, the mixture was remixed and poured into a steel mould $5 \mathrm{~cm}$ in diameter and $10 \mathrm{~cm}$ in height (Fig. 4b) in three layers. Each layer was compacted equally to remove the void from the specimen. The moulds were kept for 10-15 days to reduce the water content such that the specimens could stand without any slump. Then the specimens were removed from the mould and kept open in a tin shed room for 45-60 days to dry.

The final water content of the specimens prepared in this way was in the range of $8.38 \sim 10.30 \%$, dried for 6 to 20 weeks in Japanese weather conditions. For the measurement of the water content of adobe block, 3 specimens were collected from the top, bottom and centre of the specimen. The reported water content is the average of these three water contents. However, to understand the real behavior of adobe, water content is very important because the shear strength and stiffness of adobe significantly depend on the water content as indicated by Warren (1999). In Japanese weather conditions, it is impossible to reduce the water content up to $3.0 \%$ by natural drying for the particular soil composition. As a result, specimens were dried using an oven. To dry specimens using an oven, at first the adobe specimens with mould were kept in the oven for 3 days at $40^{\circ} \mathrm{C}$. This temperature is selected because Iran's daytime temperature (where adobe houses are being used significantly) is similar and no cracks occur in adobe at this temperature. But it was found that the water content did not decrease below $7.0 \%$ at $40^{\circ} \mathrm{C}$ (Fig. 5a). To reduce the water content further, specimens were then kept in the oven at $60^{\circ} \mathrm{C}$ for 1 more day after removal from the mould. The water content of the specimen at this stage was reduced up to $3.0 \%$. Therefore, to dry the specimens using an oven, at first the specimen with mould was kept in the oven for 3 days at $40^{\circ} \mathrm{C}$ and after that the specimen was removed from the mould and kept 1 more day at $60^{\circ} \mathrm{C}$.

Figures $5 \mathrm{~b}$ and $5 \mathrm{c}$ show the dependency of 
compressive strength and failure strain on the water content for both the oven dried and naturally dried unreinforced specimens, respectively. With the increase of water content the compressive strength of adobe decreases linearly. The compressive strength of the naturally dried specimens is also close to that of oven dried samples for the same water content. The failure strain does not depend on the water content for both the naturally and oven dried specimens. A similar trend was observed for the dependence of compressive strength and failure strain of the reinforced specimens. This means that the compressive strength decreases linearly with the increase of the water content but the failure strain does not depend on the water content. Therefore, the control of the humidity

(a)

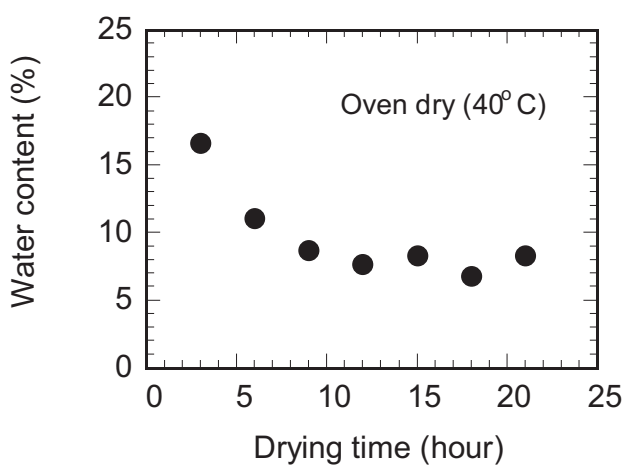

(b)

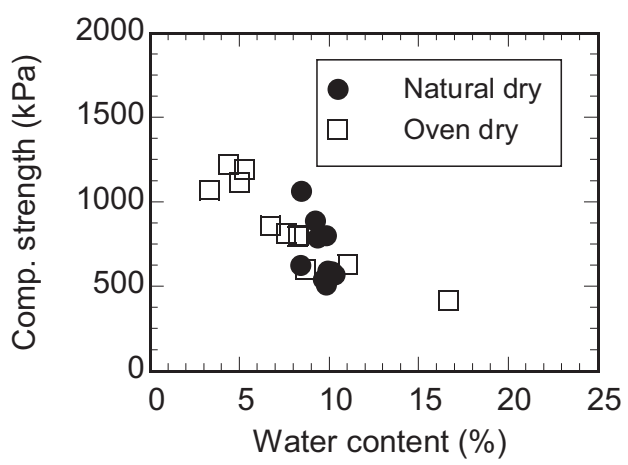

(c)

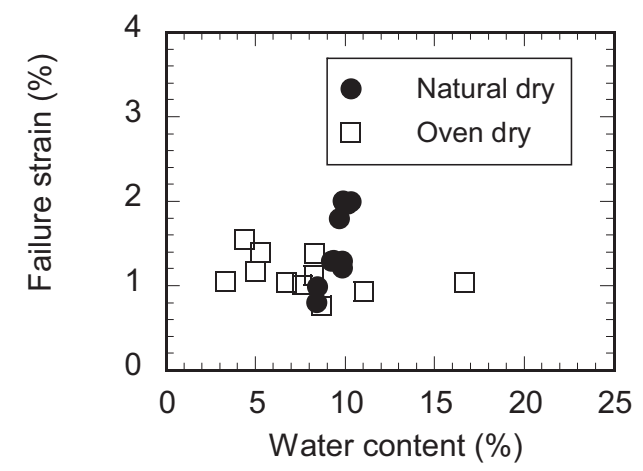

Fig. 5 Variation of: (a) water content with drying time; (b) comp. strength with water content; and (c) failure strain with water content. content of adobe may significantly contribute to their resistance in seismic conditions.

\subsubsection{Sandwich Specimen}

Several cylindrical specimens were tested under uniaxial compression; the specimens failed at the angle of 60-70 degrees. Therefore, such specimens prepared with a similar soil composition will fail at this angle. Since it was not confirmed for different soil compositions, it cannot be said that this is a general tendency for adobe material. Therefore, block parts for making sandwich specimens were obtained from a cylindrical block specimen by cutting it into two parts at an angle $60^{\circ}$ to the horizontal. Then $0.5 \mathrm{~cm}$ thick mortar was laid between the two parts to make the sandwich specimen. Figures $6 \mathrm{a}$ and $6 \mathrm{~b}$ present two parts of the specimen after cutting and a sandwich specimen, respectively. The top and bottom surfaces of the specimens were made flat using sandpaper and a sharp anti-cutter to avoid bedding errors.

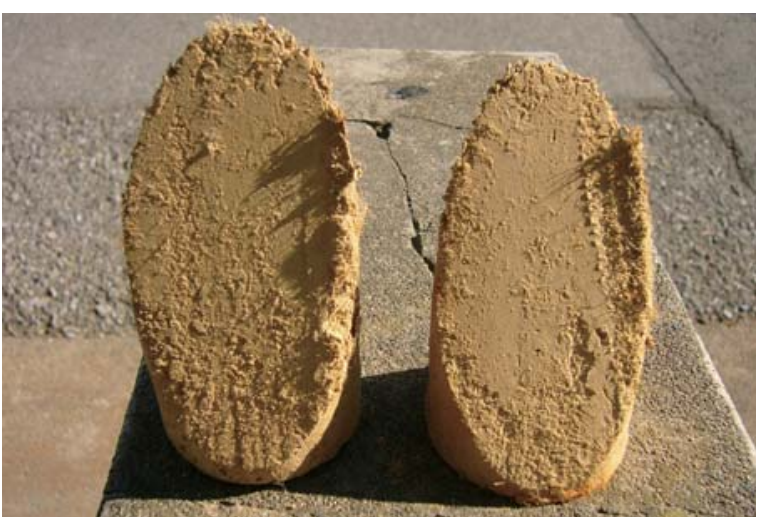

(a)

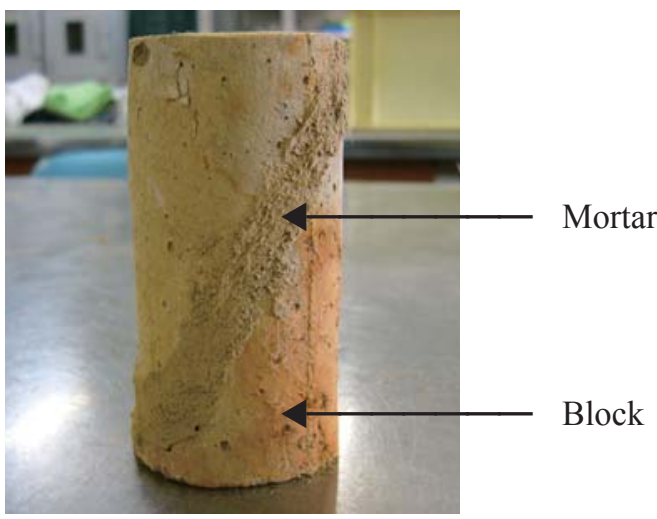

(b)

Fig. 6 Photographs showing: (a) two parts of a specimen after cut and (b) a sandwich specimen. 
Straw reinforced and gypsum stabilized specimens were prepared at the first phase in the naturally dried condition. Jute reinforced and sandwich specimens were prepared in the second phase using an oven. The water content of the naturally dried and oven dried specimens was in the range of $8.0 \sim 14.0 \%$ and $2.0 \sim 5.5 \%$, respectively. Dry density of the unreinforced and fiber reinforced specimens was in the range of $1.05 \sim 1.30 \mathrm{~g} / \mathrm{cm}^{3}$ and $0.82 \sim 1.11 \mathrm{~g} / \mathrm{cm}^{3}$, respectively. Dry density decreases slightly with the increase of the fiber content. However, the density of the specimens is significantly lower than that of the usual adobe material. Since the specimens were prepared from slurry without providing consolidation pressure, density became significantly low. This is not expected to affect the main objectives of this investigation.

\section{TEST RESULTS AND DISCUSSIONS}

\subsection{Effect of Fibers on Adobe Block}

\subsubsection{Effectiveness of Straw}

The main objective of this section is to present the effectiveness and mechanism of straw as a reinforcing material for adobe. Adobe home-makers use an arbitrarily selected amount and length of straw without knowing the effect quantitatively. Therefore, it is necessary to find the optimum content and length of straw to obtain the best seismic resistance if there is any positive effect. Crushed straw is also used instead of whole straw. So, there is potential to investigate the difference between the performance of crushed and whole straw. The size of the laboratory specimen is different from the real adobe block. Therefore, it is necessary to know the scale effect of the test specimen to simulate the test result for the real design purpose. The influence of straw content, size in length, type (i.e., crushed and uncrushed straw) and scale effect of the test specimens is described in the following sections.

\section{(1) Straw Content}

To investigate the effect of straw content, specimens were prepared from 1, 2 and $3 \mathrm{~cm}$ long straw and 'soil-sand mixture' with varying straw content from 0.0 to $3.0 \%$ by weight. Figures $7 \mathrm{a}, 7 \mathrm{~b}$ and $7 \mathrm{c}$ present the variation of compressive strength and ductility with straw content for specimens containing 1 $\mathrm{cm}, 2 \mathrm{~cm}$ and $3 \mathrm{~cm}$ long straw, respectively. Whatever the straw length, compressive strength decreased but the ductility increased with the increase of the straw content in general. The ductility of the specimens containing $1 \mathrm{~cm}$ long straw increased linearly with the increase of straw content. Ductility $\left(\mu_{\mathrm{D}}\right)$ of the specimens containing $2 \mathrm{~cm}$ and $3 \mathrm{~cm}$ long straw also increased with the increase of the straw content. But the improvement in ductility became almost constant after $1.5 \%$ straw content (Fig. $7 \mathrm{~b}$ and $7 \mathrm{c}$ ).

Figures 7d, 7e and $7 \mathrm{f}$ present the dependency of toughness on the straw content for specimens containing $1 \mathrm{~cm}, 2 \mathrm{~cm}$ and $3 \mathrm{~cm}$ long straw, respectively. For specimens containing $1 \mathrm{~cm}$ long straw, there is no particular dependency of toughness on straw content. However, specimens containing $1.5 \%$ straw had the maximum toughness, which is slightly higher than the unreinforced case. For specimens containing $2 \mathrm{~cm}$ and $3 \mathrm{~cm}$ long straw, toughness decreased up to a straw content of $1.0 \%$ and after that toughness increased again and attained a toughness value close to that of unreinforced adobe. In the case of specimens containing $2 \mathrm{~cm}$ long straw, toughness increased after 1.5\% straw content. Again, in the case of specimens containing $3 \mathrm{~cm}$ long straw, toughness decreased slightly after $1.5 \%$ straw content. From the above discussions, the following conclusions can be drawn:

- Strength of adobe block decreases with the increase of straw content irrespective of the straw length.

- Ductility increases with the increase of straw content. But the rate of improvement of ductility after $1.5 \%$ straw content is not significant for specimens containing straw longer than $1 \mathrm{~cm}$.

- The addition of straw in adobe block below 1.5\% causes decrease in toughness. But by adding straw $1.5 \%$ or more toughness can be achieved similar to that of unreinforced adobe block.

- Although the addition of this amount of straw $(1.5 \%)$ causes a decrease in compressive strength, toughness is similar (or slightly higher than) to the unreinforced case. But the improvement in ductility is significant. This means that by using $1.5 \%$ straw, collapses of adobe structure might not be prevented but they can be delayed. Therefore, $1.5 \%$ straw by weight is optimum for improving the ductility of adobe material.

The mechanisms behind the above-mentioned 


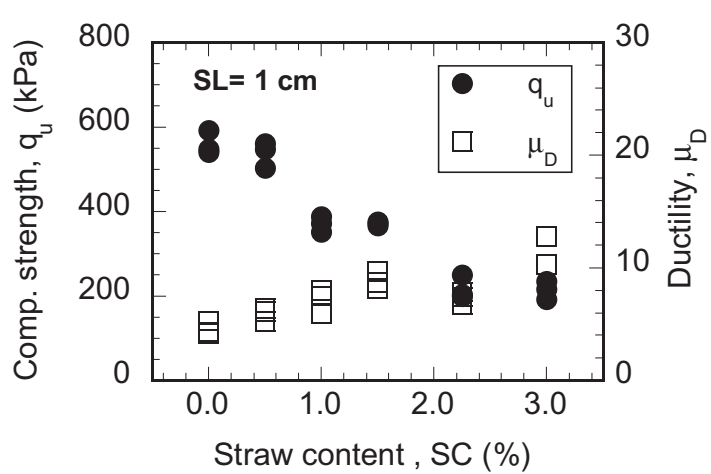

(a)

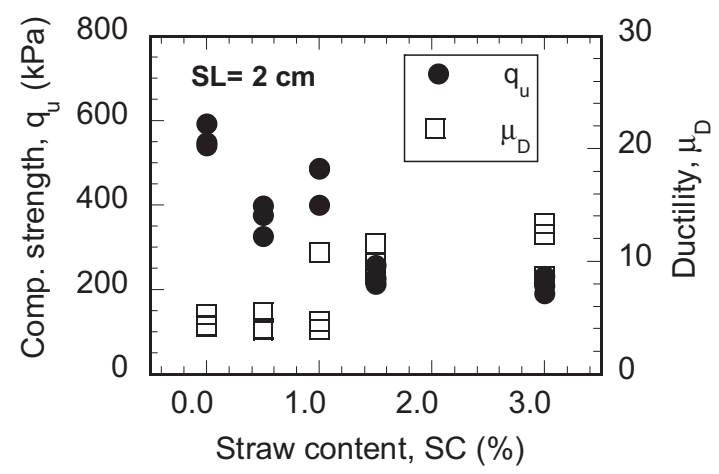

(b)

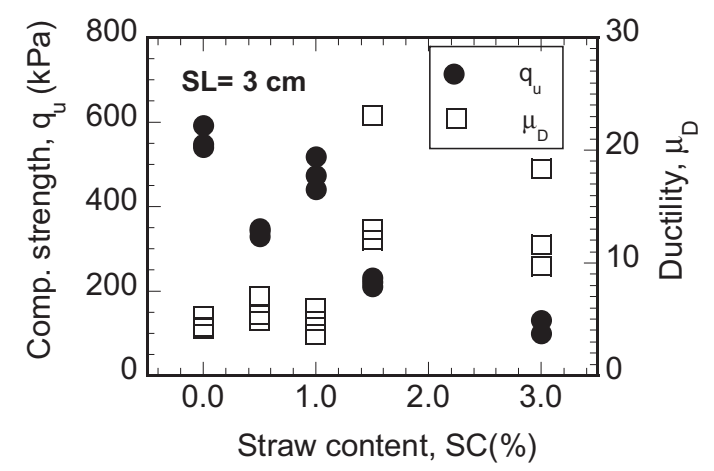

(c)

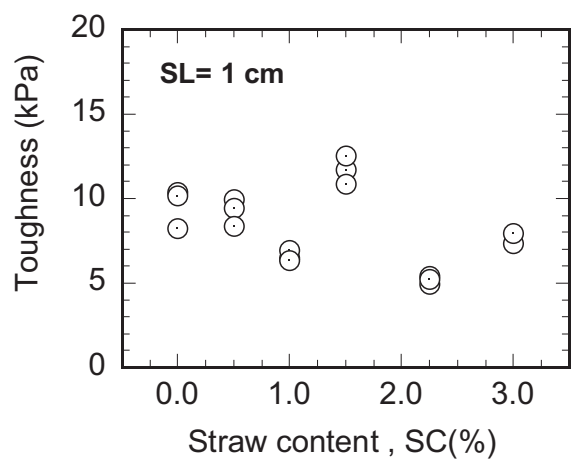

(d)

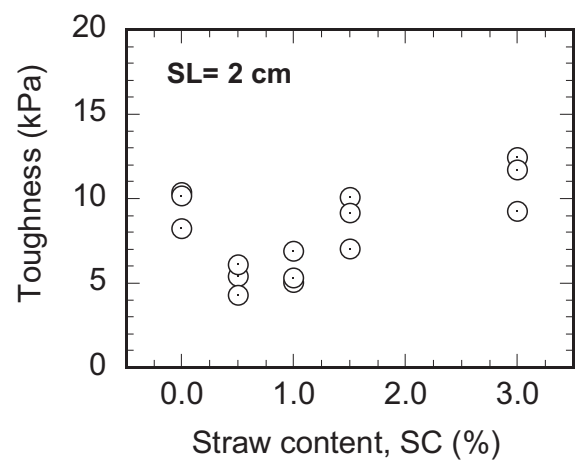

(e)

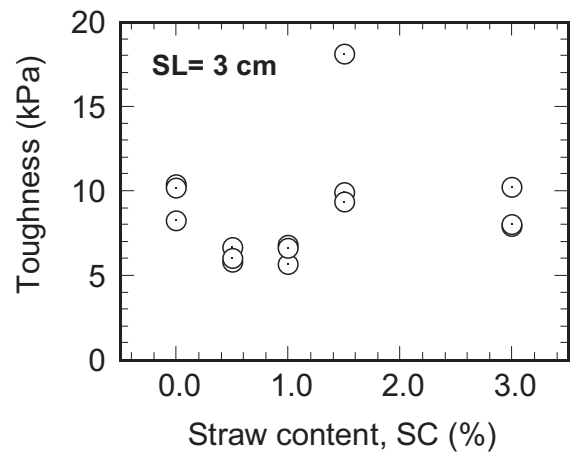

(f)

Fig. 7 Dependence of compressive strength and ductility on straw content for adobe reinforced with (a) $1 \mathrm{~cm}$ long straw, (b) $2 \mathrm{~cm}$ long straw, and (c) $3 \mathrm{~cm}$ long straw. Dependence of toughness on straw content for adobe reinforced with (d) $1 \mathrm{~cm}$ long straw, (e) $2 \mathrm{~cm}$ long straw, and (f) $3 \mathrm{~cm}$ long straw (SL= straw length).

observations can be explained as follows:

- Straw replaces the soil-sand part of the mixture. As a result, contacts between soil to soil decreases. This causes reduction in friction and thus the decreases in strength. Since straw is not flexible enough to move in phases with soil particles during the drying shrinkage of adobe, separation occurs between soil and straw. This causes micro-cracks in adobe. This might be another reason for decreasing the strength due to the addition of straw. Strength decreases with the increases of straw content since the cohesion decreases and the number and depth of cracks increase with the increase of straw content.

- Straw transmits the stresses across the cracked surface and prevents the crack from opening. In this way, straw improves the ductility of adobe material.

- Toughness is a measure of both the strength and ductility. Since the decreases in strength are more 


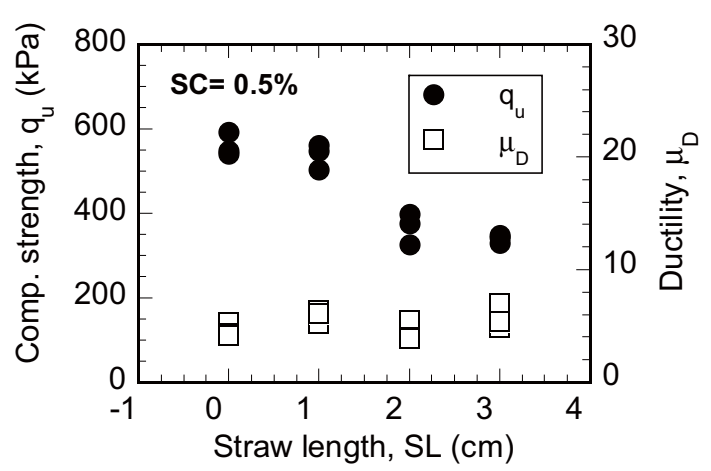

(a)

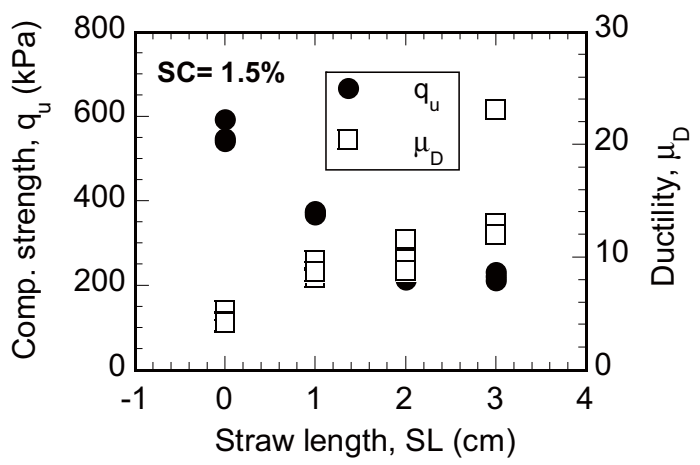

(b)

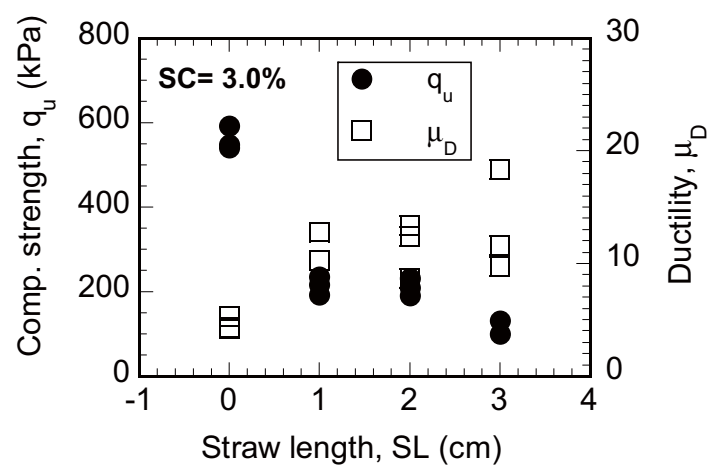

(c)

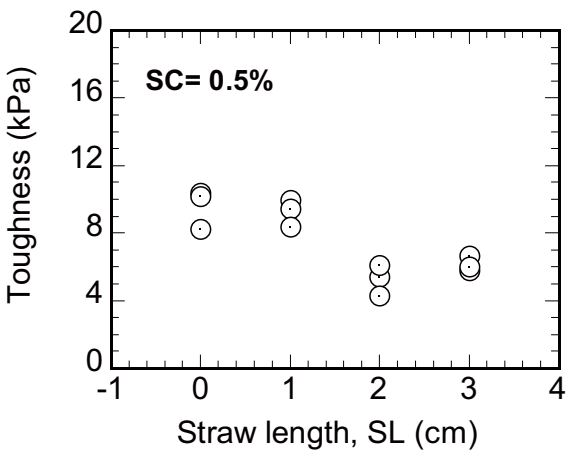

(d)

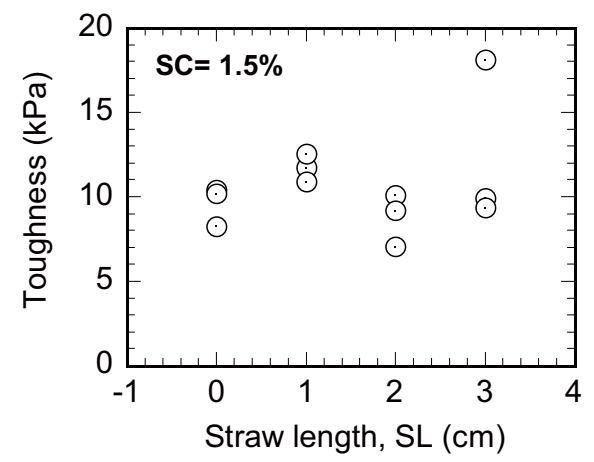

(e)

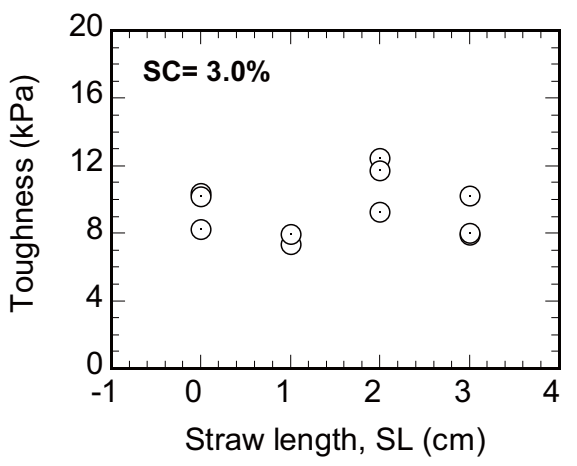

(f)

Fig. 8 Dependence of compressive strength and ductility on straw length for specimens containing (a) $0.5 \%$ straw, (b) $1.5 \%$ straw, and (c) $3.0 \%$ straw. Dependence of toughness on straw length for specimens containing (d) $0.5 \%$ straw, (e) $1.5 \%$ straw, and (f) $3.0 \%$ straw ( $\mathrm{SC}=$ straw content by weight).

significant than the improvement in ductility up to $1.0 \%$ straw content, toughness decreases up to this straw content. After that the rate of decrease in strength decreases but the ductility increases significantly with the increase of straw content and thus the toughness increases.

\section{2) Straw Length}

Figures $8 \mathrm{a}, 8 \mathrm{~b}$ and $8 \mathrm{c}$ present the dependency of compressive strength and ductility on straw length for specimens containing $0.5 \%, 1.5 \%$ and $3.0 \%$ straw (by weight), respectively. Compressive strength decreases with the increase of straw length for all cases. Ductility does not improve with the increase of straw length for the specimens containing $0.5 \%$ straw. For the other cases, ductility increases with the increase of straw length. In the case of specimens containing $1.5 \%$ straw, the improvement in ductility for speci- 


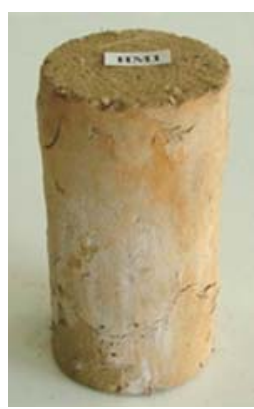

(a)

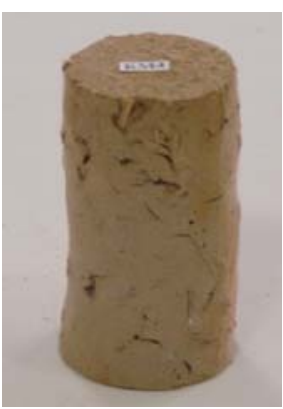

(b)

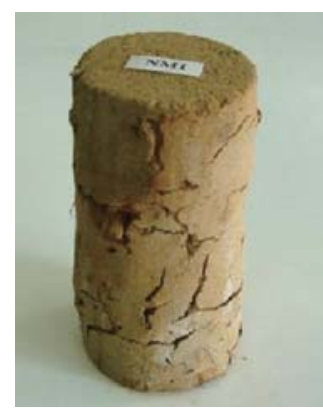

(c)

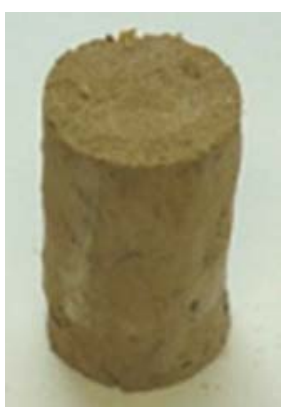

(d)

Fig. 9 Photographs of specimens containing 1.5\% straw of: (a) $1 \mathrm{~cm}$ long whole straw, (b) $2 \mathrm{~cm}$ long whole straw, (c) $3 \mathrm{~cm}$ long whole straw and (d) $3 \mathrm{~cm}$ long crushed straw.

mens containing $3 \mathrm{~cm}$ long straw from the specimens containing $2 \mathrm{~cm}$ long straw is not significant if the one extreme case is ignored (Fig. 8b). The reason for the large variation of the one case is not clear and that is why it was ignored in the discussion. The ductility of the specimens containing 3.0\% straw becomes constant after $2 \mathrm{~cm}$ long straw except for one extreme case (Fig. 8c).

Figures $8 \mathrm{~d}, 8 \mathrm{e}$ and $8 \mathrm{f}$ present the dependence of toughness on straw length for specimens containing $0.5 \%, 1.5 \%$ and $3.0 \%$ straw, respectively. Toughness decreases with the increase of straw length for specimens containing $0.5 \%$ straw. Toughness of the specimens containing $1.5 \%$ and $3.0 \%$ straw are almost independent of the straw length and the toughness value is similar to that of the unreinforced case. Therefore, on the basis of the dependency of compressive strength, ductility and toughness on straw length, the optimum length of straw is $2 \mathrm{~cm}$ to improve the seismic performance of adobe block.

Photographs of specimens containing $1.5 \%$ straw are presented in Fig. 9. The number and depth of cracks in the adobe specimens increase with the increase of straw length for the particular straw content. This might be the reason for the decrease in the compressive strength with the increase of straw length for a particular straw content.

Ductility of adobe blocks increases with the increase of straw length for the specimens containing $1.5 \%$ straw or more. Although the number of straws in the shear band is higher for the shorter straw, the bonding length is not sufficient to hold the shear band.
As the bonding length increases with the increase of the straw length, the capacity of straw to hold the shear band increases. Thus the ductility increases with the increase of straw length.

\section{3) Crushed Straw}

This section describes the effectiveness of crushed straw. To do so, the original straw was cut into 4 pieces for a particular straw $3 \mathrm{~cm}$ in length along the diameter. Typical stress-strain relationships of specimens containing whole diameter straw and crushed straw are compared in Fig. 10. The compressive strength of the specimen prepared using crushed straw is higher than that of specimens containing whole straw. However, the ductility and toughness of both the crushed and whole straw reinforced adobe are similar. This means that crushed straw is effective for improving the strength characteristics of adobe.

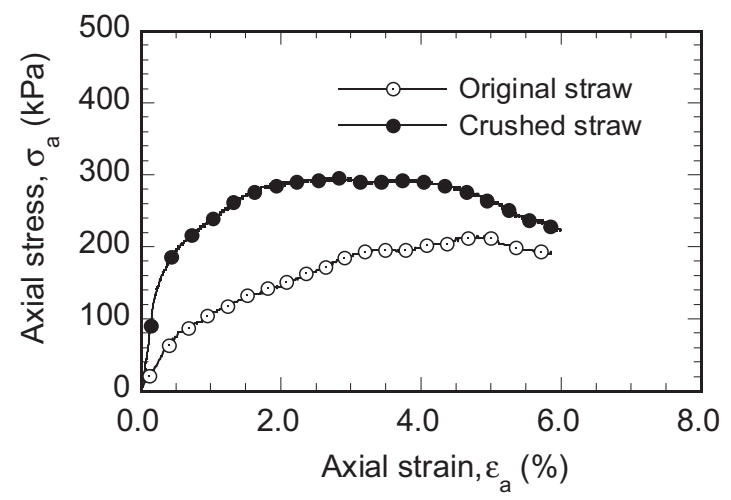

Fig. 10 Comparison of stress-strain relationships of specimens containing crushed and whole straw (straw content $=1.5 \%$; straw length $=3$ $\mathrm{cm})$. 
A photograph of a specimen prepared with crushed straw is presented in Fig. 9d. A comparison of Figs. 9c and 9d shows that the number and depth of cracks in the specimens containing crushed straw are smaller than those of the specimens containing whole straw.

The effectiveness of crushed straw is described below:

- Crushed straw is more flexible than whole straw. That's why the elasticity of the matrix with crushed straw becomes higher, which helps to prevent the micro-cracks in adobe due to drying shrinkage. Since the cracks decrease, the strength increases. Again, due to higher flexibility, the binding of crushed straw with soil is better than that of whole straw, which helps to prevent the shear band more efficiently.

- Whole straw is tubular; therefore, the volume of crushed straw is smaller than that of the whole straw for a particular weight. Therefore, the amount of soil replacement will be less for crushed straw.

- However, since the number of cracks is smaller and depth is lower in adobe block prepared with crushed straw, this will help to prevent rain infiltration that will aid its longevity.

\section{4) Scale Effect of Test Specimen}

In the current study, diameter and height of the specimens were $5 \mathrm{~cm}$ and $10 \mathrm{~cm}$, respectively. But adobe structures are generally made from blocks of larger sizes (e.g., length $=50 \mathrm{~cm}$, width $=25 \mathrm{~cm}$, height $=10 \mathrm{~cm})($ Clifton, 1977; Hakuno, 1992). In the case of laboratory specimens, fiber length varied between $1 \sim 3 \mathrm{~cm}$. However, the size of fiber that is used in real construction is different and is in the range of $5 \sim 10 \mathrm{~cm}$ (Islam, 2002). To study the effect of these factors, specimens were prepared in a larger mould 10 $\mathrm{cm}$ in diameter and $20 \mathrm{~cm}$ in height. Figures 11a and $11 \mathrm{~b}$ show the comparison of dependency of compressive strength and ductility on straw content for small and large specimens, respectively. The dependency of both the compressive strength and ductility on straw content is similar for the same straw length. This means that strength properties determined from laboratory tests using the small specimens can be used directly in estimating the design strength of real adobe structures.
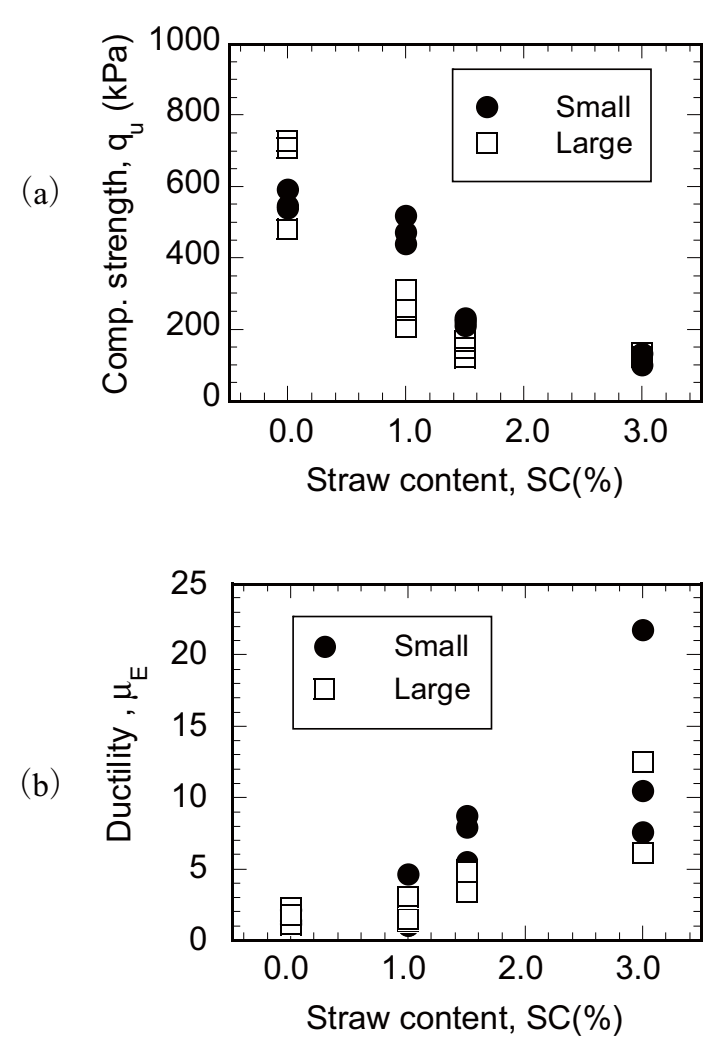

Fig. 11 Comparison of dependency of: (a) compressive strength and (b) ductility on straw content of large and small specimens (straw length $=3 \mathrm{~cm})$.

\subsubsection{Selection of Best Fiber}

The main objective of this section is to compare the effectiveness of straw with that of other fibers in order to select the most suitable fiber type. Jute and hemp were selected since these have high tensile strength and high friction. A comparison of the effectiveness of different fibers, optimum quantity and length of the most suitable fibers and their mechanism is presented in this section. To select the best fiber, specimens were prepared by mixing the soil-sand mixture with $1.0 \%$ fiber (by weight) $1.0 \mathrm{~cm}$ in length. Although the best value of the straw was known, the best value of other fiber was not, thus tests were conducted on specimens prepared with arbitrarily selected fiber content $(1.0 \%)$ and fiber length $(1 \mathrm{~cm})$.

Figure 12 presents the typical stress-strain relationships of reinforced and unreinforced adobe. The failure of unreinforced adobe is due to brittleness as observed in past earthquakes. The failure of hemp reinforced adobe is also due to brittleness. On the con- 


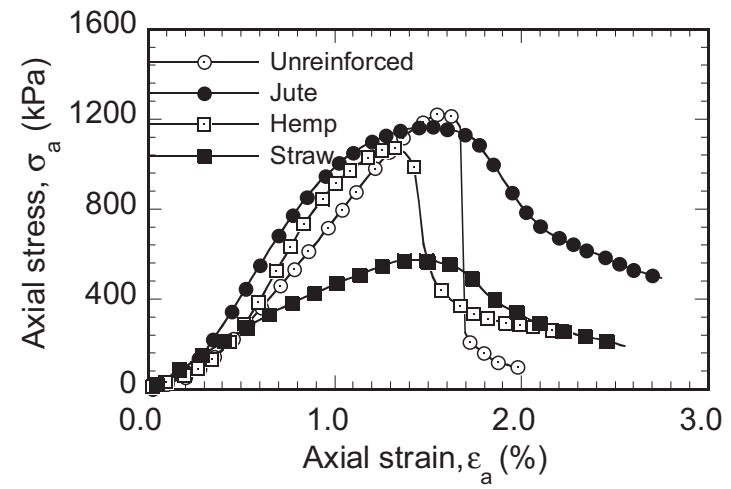

Fig. 12 Stress-strain relationships of fiber reinforced adobe.

trary, jute reinforced adobe shows ductile behavior as observed in the case of straw reinforced adobe. However, although both the jute and straw are effective for improving the ductility of adobe, the compressive strength of the straw reinforced adobe is significantly lower than that of the jute reinforced version. Again, the toughness of the jute reinforced adobe (13.0 14.8 $\mathrm{kPa})$ is higher than that of unreinforced adobe $(7.6 \sim 10.3 \mathrm{kPa})$ and other reinforced cases (6.6 9.6 $\mathrm{kPa})$. It seems that jute is the most effective among the selected fibers to improve the ductility and tough- ness of adobe block.

Figure 13 shows the failure pattern of unreinforced and reinforced specimens. The photographs show that the unreinforced adobe block has been separated into two parts (Fig. 13a). But the reinforced adobe blocks were not separated completely (Figs. $13 \mathrm{~b} \sim 13 \mathrm{~d}$ ). Fibers in the shear band protect the separation. However, parts of the hemp reinforced adobe specimen could be separated by a small push of the hand at the shear band. A closer view of the shear band of the jute reinforced adobe (Fig. 13e) reveals that jute resists the failure of the shear band and transfers the load across the opening. In this way, fiber increases the ductility of adobe block.

Jute is flexible and can bind with the soil easily which gives higher elasticity and tensile strength to the matrix. It helps the matrix to prevent the development of micro-cracks due to drying shrinkage as happened in the straw reinforced case. Again, the friction of jute to soil is higher than that of straw and hemp. These are the reasons for the higher strength of jute reinforced adobe block. Since jute is effective for im-

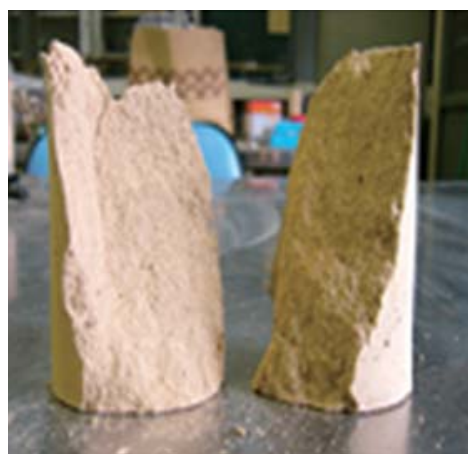

(a)

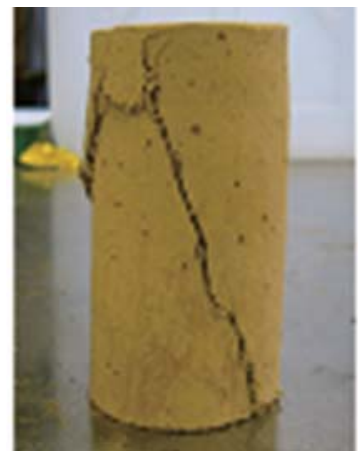

(d)

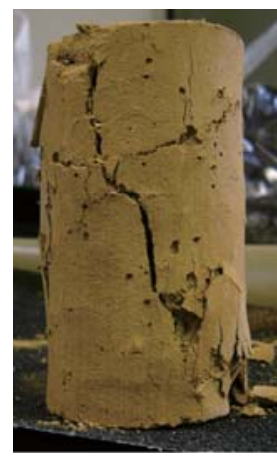

(b)

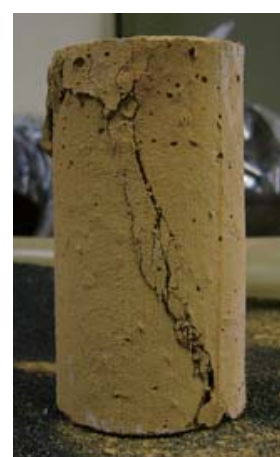

(c)

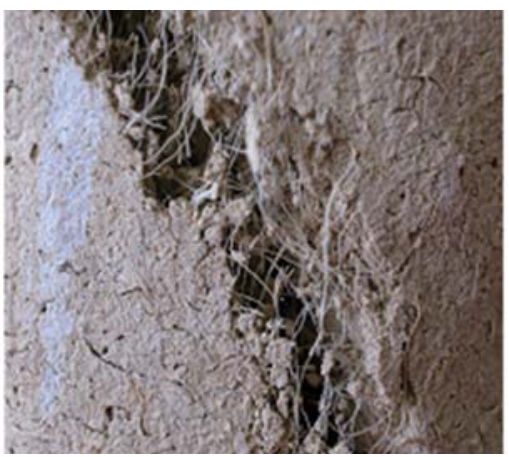

(e)

Fig. 13 Photograph showing failure pattern of: (a) unreinforced adobe; (b) straw reinforced adobe; (c) hemp reinforced adobe; (d) jute reinforced adobe and (e) close view of shear band of jute reinforced adobe. 
proving the ductility with a slight decrease in strength, jute fiber reinforced adobe has significantly higher toughness than the unreinforced type. It is clear that fiber like jute with high flexibility, friction and tensile strength is the most suitable fiber for improving the ductility and toughness of adobe block.

Since jute is the most effective for improving the seismic resistance of adobe material, the influence of jute content and size in length on the seismic performance of adobe was investigated.

\section{(1) Jute Content}

Specimens were prepared using $1 \mathrm{~cm}$ long jute by varying the jute content from 0.5 to $4.0 \%$ by weight. Figure 14a shows the variation of compressive strength and ductility on jute content. Compressive strength decreases with the increase of the jute content. However, the rate of decrease in strength beyond $2.0 \%$ jute content is not remarkable. Again, we see that ductility increases with the increase of jute content. But the rate of improvement after the 2.0\% jute content is very low. Figure $14 \mathrm{~b}$ shows the variation of toughness with jute content. The toughness increases with the increase of the jute content up to $2.0 \%$ and after that toughness decreases. From the above

(a)

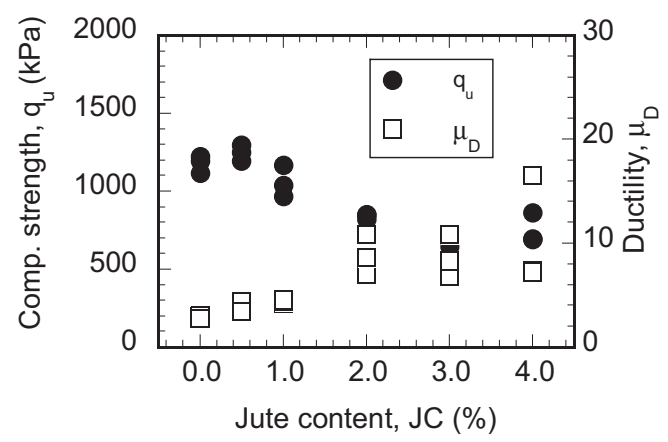

(b)

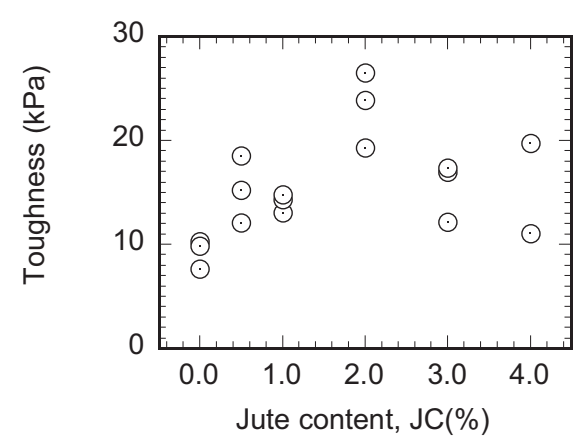

Fig. 14 Dependence of: (a) compressive strength and ductility; and (b) toughness on jute content (jute length $=1 \mathrm{~cm}$ ). observations, it is clear that $2.0 \%$ jute by weight is optimum for improving the ductility and toughness of adobe block.

Strength and toughness of unreinforced adobe mainly come from the soil to soil friction and cohesion between soil to soil. But in the case of the fiber reinforced type, they come from the composite bonding of soil with jute and friction between soil to fiber as well as fiber to fiber. After $2.0 \%$ jute content, the bonding between fibers might become prominent, which is weaker than the bonding between soil to fiber and soil to soil. This means that the composite matrix of the soil and jute fiber up to $2.0 \%$ is optimum for improving the toughness of adobe block.

(2) Jute Length

To investigate the effect of the jute length, specimens were prepared using $2.0 \%$ jute for different jute lengths using the 'soil-sand mixture'. Jute length varied from 0.5 to $3 \mathrm{~cm}$. Figure 15a presents the dependency of the compressive strength and ductility on jute length. Figure $15 \mathrm{~b}$ shows the variation of toughness with jute length. The compressive strength of the jute reinforced adobe is lower than that of the unreinforced adobe. But the compressive strength of

(a)
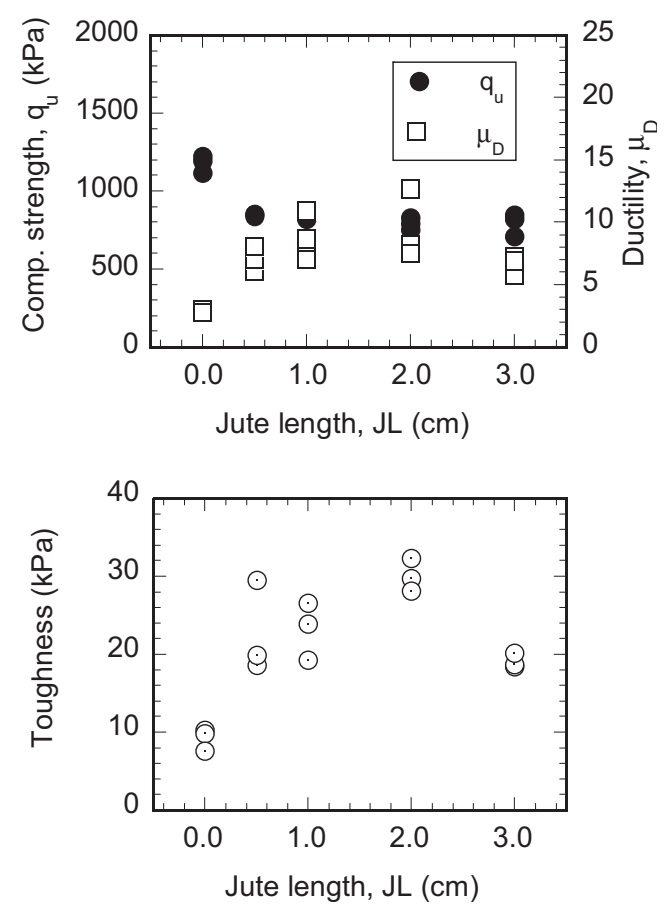

Fig. 15 Dependence of: (a) compressive strength and ductility; and (b) toughness on jute length (jute content $=2.0 \%$ ). 
the jute reinforced adobe does not change with the increase of jute length. Both the ductility and toughness increase with the increase of jute length up to $2 \mathrm{~cm}$ and after that both the ductility and toughness decrease. Therefore, to obtain the maximum ductility and toughness the length of jute should be $2 \mathrm{~cm}$. The mechanism behind this phenomenon is yet to be clarified. However, the size in length might depend on the size of the block.

\subsection{Strength of Adobe Block}

\subsubsection{Effect of Gypsum}

It is found that fibers are effective for improving the ductility but not the strength of adobe. This section presents the effectiveness of gypsum. Specimens were prepared by varying the gypsum content 0.0 to $13.0 \%$ by weight. Variation of the compressive strength and ductility with the gypsum content is plotted in Fig. 16a. With the increase of the gypsum content, compressive strength increases but there is no improvement in the ductility. Therefore, gypsum is effective for improving the strength characteristics only. In practical terms, this means that by using gypsum stabilized mud bricks, the thickness of the outer load bearing walls can be reduced substantially. Gyp-
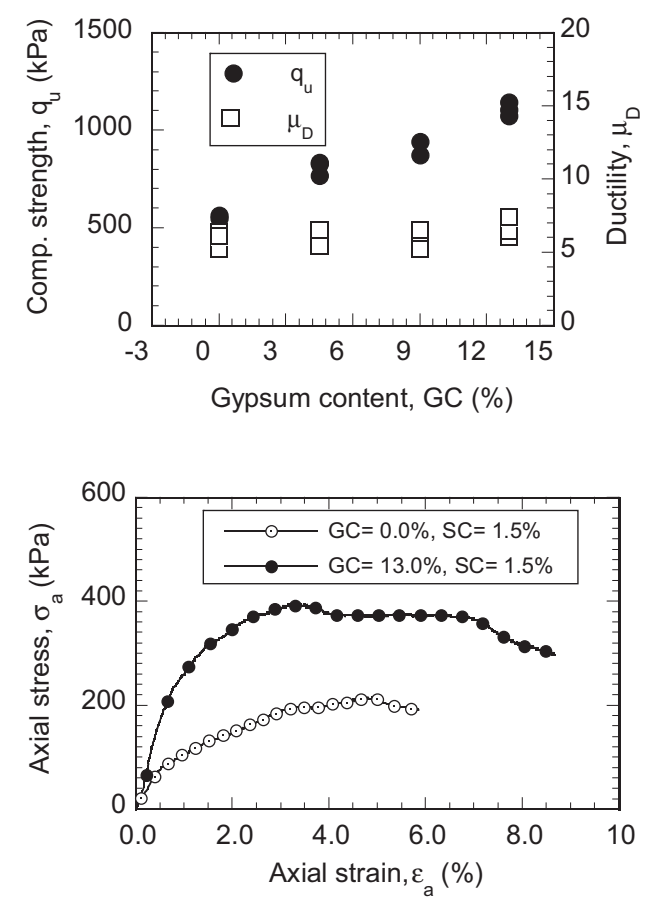

Fig. 16 (a) Dependence of compressive strength and ductility on gypsum content and (b) comparison of stress-strain relationship $(\mathrm{GC}=$ gypsum content; $\mathrm{SC}=$ straw content). sum gives cohesion to the soil and that's why strength increases. Figure 16b shows a comparison of the typical stress-strain relationship of specimens containing $1.5 \%$ straw and specimens containing $1.5 \%$ straw as well as $13.0 \%$ gypsum together. For both cases, the straw length is $3 \mathrm{~cm}$.

The strength of the specimens containing gypsum and straw together is higher than that of the specimens containing straw only. There was no crack in the specimens containing gypsum and straw together. But the specimens containing only straw had significant cracks (Fig. 9c). This means that the addition of gypsum prevents cracking of adobe block. This might be the reason for the higher strength. Moreover, adobe reinforced with both the straw and gypsum together might be more accepted by the user from an aesthetic viewpoint since there is no crack on the surface of such specimen.

\subsubsection{Effect of Clay Content}

In the previous sections, the effect of different fibers and gypsum was described. Jute is found to be the most effective among the selected fibers. In this context, it is necessary to clarify the effect of jute fiber

(a)

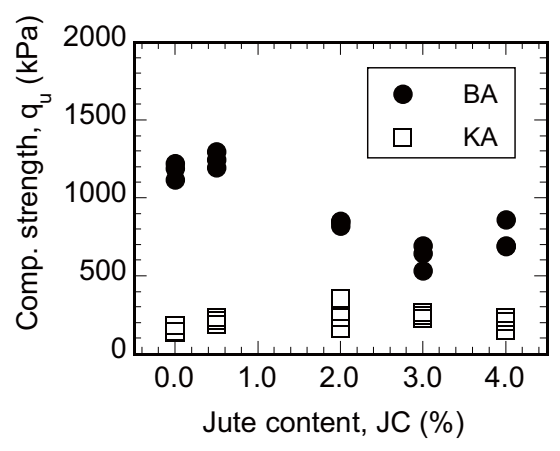

(b)

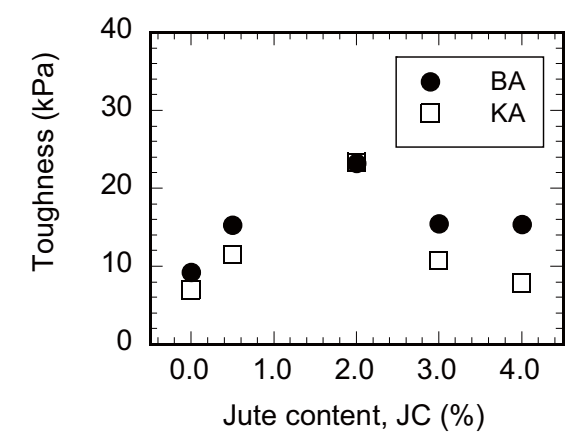

Fig. 17 Comparison of dependence, of, (a) compressive strength and (b) toughness on jute content for Bentonite Adobe (BA) and Kaolin Adobe (KA) [jute length $=1 \mathrm{~cm}]$. 
on adobe with different soil compositions. Specimens were prepared using Kaolin clay instead of Bentonite clay. This means that specimens were prepared by mixing Acadama clay, Toyoura sand and Kaolin at the ratio of 2.5:1.0:0.6. Figure 17a compares the strength of 'Bentonite Adobe' (BA) and 'Kaolin Adobe' (KA). The strength of BA is significantly higher than that of the KA. On the contrary, the failure strain of KA is higher than that of BA (not presented here). The variation of toughness (Fig. 17b) with jute content shows that in both cases, specimens containing $2.0 \%$ jute have the maximum toughness. It is clear that $2.0 \%$ jute by weight is optimum for improving the seismic performance of adobe block. However, it is also clear that soil composition has a significant effect on the properties of adobe material. Therefore, suitable soil selection is very important for the earthquake resistant performance of adobe. The difference in the properties might be due to the difference in plasticity (Table 1). Further investigations are necessary to clarify this effect.

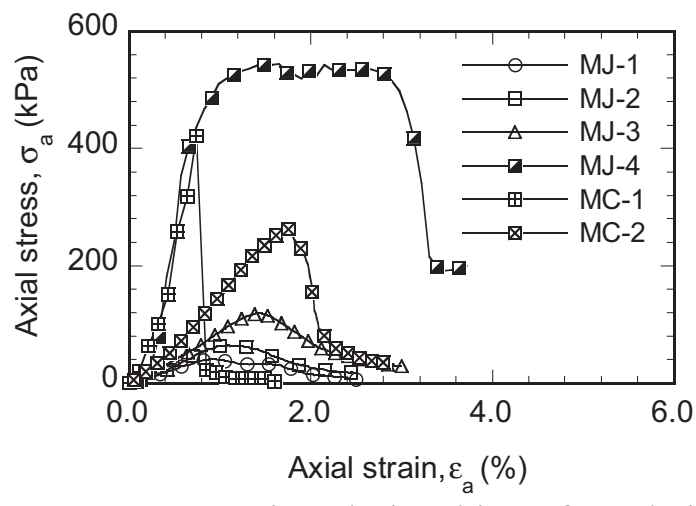

Fig. 18 Stress-strain relationships of sandwich specimens (jute length $=1 \mathrm{~cm}$ ).

\subsection{Bonding between Block and Mortar}

The improvement of bonding between block and mortar is the key issue for the improvement of seismic resistance of adobe structures. The effect of jute and cement on mortar properties evaluated by uniaxial compression tests is presented in this section. Compositions, physical properties and test results of the sandwich specimens are presented in Table 2 and Fig. 18.

\subsubsection{Effect of Jute}

Both block and mortar of the specimens of the MJ-1 group are unreinforced. The jute content of the block part of the specimens of the MJ-2 group is $0.5 \%$ by weight but the mortar is unreinforced. Both the block and mortar part of the specimens of the MJ-3 and MJ-4 groups contain 1.0\% and 2.0\% jute by weight, respectively. The effect of jute on the sandwich specimen was investigated up to $2.0 \%$ by weight since it was found optimum for block (Section 3.1.2).

The compressive strength of the unreinforced block and sandwich specimen is $1,180 \mathrm{kPa}$ and 33 $\mathrm{kPa}$, respectively. This means that the strength of the unreinforced sandwich specimen is significantly lower than that of the block specimen. The strength of the specimens of the MJ-2 and MJ-3 groups is higher than that of the unreinforced specimens (MJ-1). However, the strength of these groups (i.e., MJ-2 and MJ3 ) is also significantly lower than the block strength. The compressive strength and failure strain of the sandwich specimen of the MJ-4 group are $560 \mathrm{kPa}$ and $2.43 \%$, respectively. Although the compressive strength of the sandwich specimen of this group (MJ4 ) is less than that of the unreinforced block strength, both the ductility (6.2 13.7) and toughness (9.10 16.5 $\mathrm{kPa}$ ) of this sandwich specimen are higher than that

Table 2. Description and characteristics of sandwich specimens

\begin{tabular}{|c|c|c|c|c|c|}
\hline \multirow[t]{2}{*}{ Group } & \multirow{2}{*}{$\begin{array}{c}\text { Block }(\%) \\
\text { Jute } \\
\end{array}$} & \multicolumn{2}{|c|}{ Mortar (\%) } & \multirow{2}{*}{$\begin{array}{l}\text { Strength } \\
(\mathrm{kPa})\end{array}$} & \multirow{2}{*}{$\begin{array}{c}\text { Failure strain } \\
(\%)\end{array}$} \\
\hline & & Jute & Cement & & \\
\hline MJ-1 & - & - & - & $26 \sim 40$ & $0.94 \sim 1.38$ \\
\hline MJ-2 & 0.5 & - & - & $63 \sim 74$ & $1.00 \sim 1.32$ \\
\hline MJ-3 & 1.0 & 1.0 & - & $92 \sim 175$ & $1.38 \sim 2.15$ \\
\hline MJ-4 & 2.0 & 2.0 & - & $455 \sim 703$ & $1.88 \sim 2.80$ \\
\hline MC-1 & 1.0 & - & 9.0 & $326 \sim 482$ & $0.70 \sim 0.80$ \\
\hline MC-2 & 1.0 & 1.0 & 9.0 & $150 \sim 262$ & $1.25 \sim 1.65$ \\
\hline
\end{tabular}


of the block. Thus by adding $2.0 \%$ jute in both the block and mortar, the earthquake resistance of adobe structures can be improved.

Photographs of Fig. 19 show the failure pattern of the sandwich specimens. Many cracks are seen in the unreinforced mortar of the specimen of the MJ-1 group (Fig. 19a). The specimen of the MJ-2 group had similar cracks. Cracks in the mortar are the main reason for the low strength and poor bonding of unreinforced mortar. On the contrary, however, there are no cracks in the jute reinforced mortar of the specimen of the MJ-4 group (Fig. 19b). Similarly, the mortar of the specimens of the MJ-3 group had no cracks. This means that jute is effective for preventing the shrinkage cracks in mortar. The failure surface and pattern of the jute reinforced mortar (MJ-4) indicate that some parts of the mortar came out during failure. If the bond/cohesion between block and mortar is weak, separation between block and mortar occurs. But if the bond is strong, composite failure (i.e., failures along the interface between mortar and block, and/ or within mortar) occurs. In this case, both failures along the interface between mortar and block, and within mortar have occurred, indicating that the bond between the block and mortar was stronger in the case of MJ-4. Thus, the addition of fibers in mortar provides better coherence between block and mortar. This might account for the difference in the failure pattern of MJ-4 and others. This phenomenon can be observed clearly from the stress-strain relationship of the specimens of the MJ-4 group (Fig. 18). The stress-strain relationships of the specimen of the MJ-4 group are different from the others. The specimen of this group can continue with the peak strength by increasing the strain up to a certain limit and after that the strength decreases suddenly. Before bond failure (between block and mortar) the block-mortar system (sandwich specimen) acts as a single system. When the bond between the block and mortar starts to fail, then it goes for immediate failure. The peak of MJ-4 remains constant until the bond failure initiates.

From the above observations and discussions, it is clear that the addition of $2.0 \%$ jute by weight to the block and mortar is the most effective way of improving the ductility and toughness of sandwich specimens. Jute prevents shrinkage cracks and provides coherence between block and mortar. These might explain the better performance of jute reinforced mortar.

\subsubsection{Effect of Cement}

The block part of the specimens of the MC-1 and MC-2 groups (Table 2) contains $1.0 \%$ jute by weight. But the mortar part of the MC-1 contains only $9.0 \%$ cement (by weight) while the mortar part of the specimens of the MC-2 group contains $1.0 \%$ jute and $9.0 \%$ cement (by weight) together.

The compressive strength of the sandwich specimen of the MC-1 group (410 kPa) is significantly higher than that of the unreinforced mortar $(33 \mathrm{kPa})$. This means that cement is effective for improving the mortar strength. But the failure strain is significantly lower $(0.70 \sim 0.80 \%)$ than that of the unreinforced version $(0.94 \sim 1.38 \%)$ and the failure is sudden (Fig. 18). Many cracks are observed in the mortar of this group (Fig. 19c) indicating that cement cannot prevent shrinkage cracks in the mortar. Continuous failure occurred through the mortar in this case. Cement gives cohesion to the matrix and that is why the strength increases. But poor coherence between block and mortar is responsible for the brittle failure.

The compressive strength of the specimens of the MC-2 group is $196 \mathrm{kPa}$, which is higher than that of the unreinforced mortar strength. But the strength is significantly lower than the cement reinforced mortar. However, the failure strain is higher than that of unreinforced and cement reinforced mortar. Figure 19d shows that there is no crack in the mortar of the specimens of the MC-2 group. Thus jute with cement is also effective for preventing cracks in the mortar. However, the strength of the MC-2 group is expected to be higher than that of MC-1. The reason for the lower strength of MC-2 might be due to the lack of proper hydration of the cement. To make the specimens, the same amount of water was added to make the slurry. Since the specimens of the MC-2 group contain both jute and cement, both jute and cement absorbed water from the matrix. Therefore, the remaining water (after the saturation of jute) might not be sufficient for the complete hydration of cement with time.

From the above discussion, it is clear that ce- 


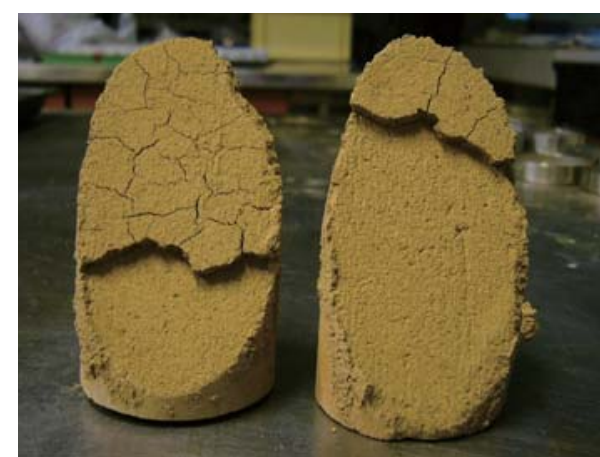

(a)

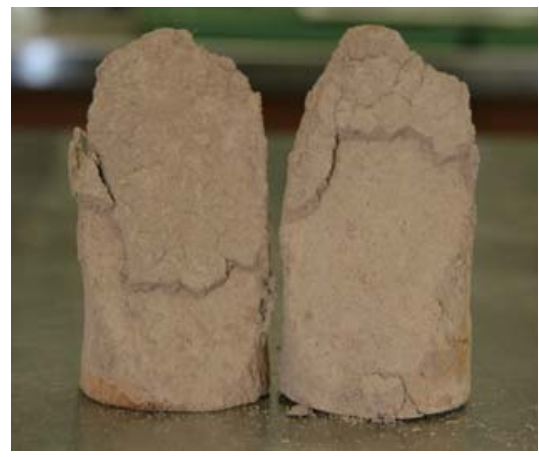

(c)

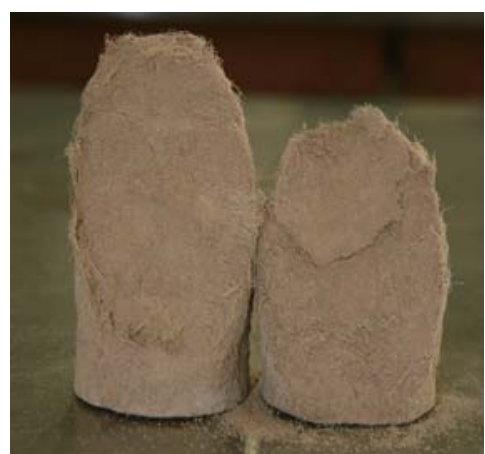

(b)

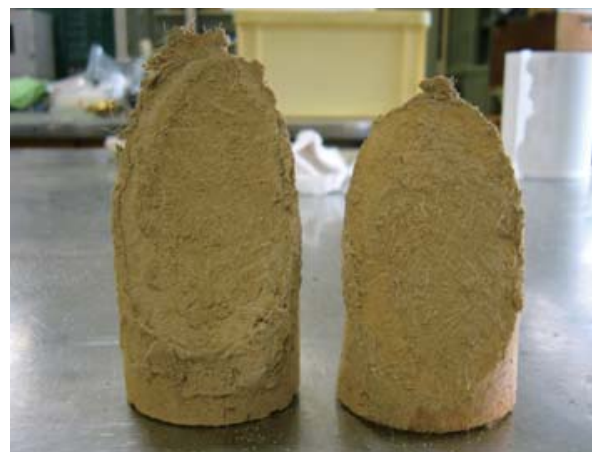

(d)

Fig. 19 Photographs of sandwich specimens after failure, for Group: (a) MJ-1 (block and mortar: unreinforced), (b) MJ-4 (block and mortar: reinforced by 2.0\% jute), (c) MC-1(block: 1.0\% jute; mortar: 9.0\% cement) and (d) MC-2 (block: $1.0 \%$ jute; mortar: $1.0 \%$ jute and $9.0 \%$ cement).

ment is effective for improving the strength of mortar. But cement is not effective for preventing crack or improving the ductility of the sandwich.

\section{CONCLUSIONS}

The development of cost effective solutions for improving the seismic resistance of adobe structures is an important and challenging issue for earthquake engineers to reduce the earthquake hazard of poor people in developing countries. Natural fibers (straw, hemp and jute) and cementing materials (cement and gypsum) were selected to improve the block and mortar properties of adobe. Uniaxial compression tests were conducted on cylindrical blocks and sandwich specimens in order to evaluate the effect of the proposed reinforcing materials on block and mortar, respectively. The main conclusions obtained are:

(1) Compressive strength decreases with the increase of the water content without affecting the failure strain. So, the control of humidity content of adobe may significantly contribute to their resistance in seismic conditions.
(2) Straw is effective for improving the ductility of adobe at the cost of compressive strength. However, there is an optimal quantity (i.e., $1.5 \%$ by weight) and length of straw (i.e., $2 \mathrm{~cm}$ ) to improve the ductility of adobe block. The strength of adobe block prepared with crushed straw is higher than that of the specimens prepared with whole straw. Straw in the shear band transfers the stress across the crack and prevents the crack from opening. Hence, straw improves the ductility. Reduction in the friction between soil to soil due to the replacement of the soil-sand part by straw and micro-cracks that were caused by straw are responsible for the reduction of strength. Since the cracks in the adobe block increase with the increase of both the straw content and length, strength decreases with the increase of both the straw content and length. The reason behind the better performance of crushed straw might be its higher flexibility, which helps to prevent the shrinkage cracks in the adobe block.

(3) Jute is also effective for improving the ductility 
while hemp is not effective for improving the ductility. Jute seems to be the most effective among the selected fibers since jute improves both the ductility and toughness of adobe material with slight decreases in compressive strength. There are also an optimal jute content and jute length, which are $2.0 \%$ by weight and 2 $\mathrm{cm}$, respectively. The higher flexibility, friction to soil, and the tensile strength of the jute fiber in comparison with those of straw and hemp might be the reason for its best performance among the selected fibers.

(4) Gypsum improves the strength of the adobe block. Gypsum gives cohesion to the matrix and thus the strength increases. Soil composition also plays a significant role in the seismic resistance of adobe. Both the compressive strength and failure strain are dependent on the soil composition.

(5) The strength of the 'block and mortar sandwich' is significantly lower than that of adobe block. Cracks and poor bonding of unreinforced mortar are the main causes for its poor performance. Cement improves the strength of the mortar significantly but cannot improve the ductility of the sandwich specimen. Jute is effective for improving both the strength and ductility of the sandwich specimen. Jute prevents the shrinkage cracks in the mortar and the sewing action of jute fibers gives better bonding between block and mortar. These are the mechanisms behind the better performance of jute reinforced mortar.

(6) Finally, natural fibers like jute and cementing materials like cement or gypsum can be added to block and mortar to improve the earthquake resistance of adobe structures. The cost of jute reinforcement for a standard adobe house is about 30 US dollars, which is affordable to low income people in developing countries.

The longevity of natural fiber in adobe depends on the water content of the block and mortar. Adobe structures are mostly used in arid regions and the water content of adobe in those places is very low $(2 \sim 3 \%)$. Fibers are not expected to be decomposed at such low water content even if they are used in the exterior walls. In heavy rainfall areas some coating/ plaster can be used to protect against the infiltration of water into adobe walls, which is under investigation. However, this study focuses only on the improvement of adobe block and mortar properties. Further investigations are being conducted to improve the structural integrity using low cost materials (bamboo, cane, and jute mesh).

\section{ACKNOWLEDGEMENTS}

The first author is grateful to Prof. H. Watanabe of Saitama University, Japan for his guidance. This research was partially supported by the Japan Society for the Promotion of Science (JSPS), Grant-in-Aid for JSPS Fellows, Grant Number: 17005291. The authors are also grateful to the Iranian Cultural Heritage Organization for providing old adobe. They express their deep gratitude to Mr. Honda, Mr. Kin and Mr. Kamata, former graduate students of Saitama University for their participation during tests.

\section{REFERENCES}

Arya, A. S., 2000. Non-engineered construction in developing countries - an approach toward earthquake risk prediction, Proc. of 12th World Conf. on Earthquake Engrg., Auckland, New Zealand, Paper No. 2824.

Bariola, J. and Sozen, M. A., 1990. Seismic tests of adobe walls, Earthquake Spectra, 6 (1), 37-56.

Binici, H., Aksogan, O. and Shah, T., 2005. Investigation for fiber reinforced mud brick as building material, Construction and Building Materials, 19, 313-318.

Blondet, M., Garcia, G.V. and Brzev, S., 2003. Earthquake-Resistant Construction of Adobe Buildings: A Tutorial, EERI/ IAEE World Housing Encyclopedia, http://www.worldhousing.net/Tutorials/AdobeTutorial/AdobeTutorial.asp.

Blondet, M., Torrelva, D., Vargas, J. Velasquez, J. and Tarque, N., 2006. Seismic reinforcement of adobe houses using external polymer mesh, First European Conf. on Earthquake Engrg. and Seismol., Geneva, Switzerland, Paper No. 632.

Boduroglu, M. H., 1989. Rural buildings in Turkey that have suffered damages in recent earthquakes and their main causes, Bull. Int. Inst. Seismol. Earthquake Engrg., 23, 359-380.

Brown, P. W., Robbins, C. R. and Clifton, J. R., 1978. Factors affecting the durability of adobe structures, US National Bureau of Standards, Technical Note 1495, US Department of Commerce, Washington DC. 
Clifton, J. R., 1977. Preservation of historic adobe structures - a status report, TBS Technical Note 934, US Department of Commerce/National Bureau of Standards.

Ginell, W. S., Thiel Jr., C. C., Tolles, E. L. and Webster, F. A., 1995. Seismic stabilization of historic adobe buildings, Structural Studies of Historical Buildings IV, Сотриtational Mechanics Publications, Southampton, United Kingdom and Boston, Dynamics, Repairs \& Restoration, 2, 53-60.

Hakuno, M., 1992. Earthquake damage: the mother of earthquake engineering. Learning from observations of earthquake damage, Kajima Institute, Publishing, Tokyo, Japan.

Hammond, A. A., 1973. Prolonging the life of earth buildings in the tropics, Building Research and Practice, 154-163.

Hossein-Javaheri, J., 1972. Sun-dried buildings in Khorasan and their resistance to earthquake, J. Earth and Space Physics, 1 (2), 7-12.

Houben, H. and Guillaud, H., 1994. Earth Construction - a Comprehensive Guide, 4-15, ITDG Publication, London.

Isik, B., Ozdemir, P. and Boduroglu, H., 1999. Earthquake aspects of proposing gypsum stabilized earth (alker) construction for housing in the southeast (gap) area of Turkey, Intl. workshop on recent earthquakes and disaster prevention management, Middle East Technical University, Turkey, 105-109.

Islam, M. S, Honda, K. and Iwashita, K., 2006. Improvement of earthquake resistance of adobe structures, First European Conf. on Earthquake Engrg. and Seismol., Geneva, Switzerland, Paper No. 146.

Islam, M. S., 2002. Research on Earthquake Resistant Reinforcement for Adobe Structures, PhD Thesis, Department of Civil and Environmental Engineering, Saitama University, Japan.

Krätzig, W. B. and Meskouris, K., 1998. Assessment of seismic structural vulnerability as a low-cycle-fatigue process, Proc. of the $11^{\text {th }}$ European Conf. on Earthquake Engrg., In Bisch, P., Labb, P., Pecker, A. (Eds.), Invited Lectures, Paris, A. A. Balkema, Rotterdam, 440-457.

Meli, R., Hernandez, O. and Padilla, M., 1980. Strengthening of adobe houses for seismic actions, Proc. of the $7^{\text {th }}$ World Conf. on Earthquake Engrg, Istanbul, Turkey, 4,
465-472.

Morris, H. W., 1993. The strength of engineered earth buildings, Proc., IPENZ, Annual Conf., Sustainable Development, Hamilton, 660-671.

Ottazzi, G., Yep, J., Blondet, M., Villa-Garcia, G. and Ginocchio, J. F., 1988. Shaking table tests of improved adobe masonry houses, Proc. of the 9th World Conf. on Earthquake Engrg, Tokyo-Kyoto, Japan, 8, 1123-1128.

Paola, M. A. J., Meguro, K., Navaratnarajah, S., Ramesh, G. and Nasrollahzadeh, N., 2006. Seismic behaviour of masonry houses retrofitted with PP-band meshes evaluated with shaking table test, European Conf. on Earthquake Engrg. and Seismol., Geneva, Switzerland, Paper No. P261B.

PWD Schedule, 2002. Schedule No. 45 for concrete, Schedule No. 68 A \& B for steel, Chapter-Materials, Public Works Department, Govt. of Bangladesh, Dhaka, Bangladesh.

Scawthorn, C. and Becker, A., 1986. Relative benefits of alternative strengthening methods for low strength masonry buildings, Proc. of the Third US National Conf. on Earthquake Engrg., Charleston, South Carolina, 3, 2023-2034.

The Japanese Geotechnical Society, Tokyo, 1990. JSF Standards, 430-440 (in Japanese).

Tolles, E. L., Kimbro, E. E., Webster, F. A. and Ginell, W. S., 2000. Seismic Stabilization of Historic Adobe Structures, Final report of the Getty Seismic Adobe Project, The Getty Conservation Institute, Los Angeles, USA.

Tolles, E. L., Webster, F. A., Crosby, A. and Kimbro, E. E., 1996. Survey of Damage to Historic Adobe Buildings after the January 1994 Northridge Earthquake, GCI Scientific Program Report, The Getty Conservation Institute, Los Angeles, USA.

Tomaževič, M., 1999. Earthquake-Resistant Design of Masonry Buildings, Series on Innovation in Structures and Construction-Vol. 1, 5-33, editor A.S. Elnashai \& P. J. Dowling, Imperial College Press, London.

Vargas, J., Bariola, J., Blondet, M. and Mehta, P. K., 1986. Seismic strength of adobe masonry, Material and Structures, Vol. 19, pp. 253-258.

Warren, J., 1999. Conservation of Earth Structures, Butterworth-Heinemann: Oxford, 68-73.

World Bank Statistics, $2004<$ www.nationmaster.com> as retrieved on December 12, 2006. 
